EGG-EP-9842

Distribution Category: UC -257

EGG-EP--9842

DE92 003362

\title{
FEASIBILITY STUDY:
}

APPLICATION OF THE GEOPRESSURED-GEOTHERMAL RESOURCE TO PYROLYTIC CONVERSION OR DECOMPOSITION/DETOXIFICATION PROCESSES

\author{
H. Alan Propp \\ Alan E. Grey \\ Jane Negus-de Hys \\ Martin M. Plum \\ Daryl R. Haefner
}

September 1991

Prepared for the

U.S. Department of Energy

Field office, Idaho

Under DOE Contract No. DE-ACO7-761D01570

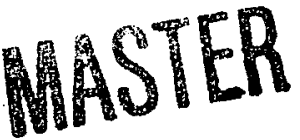




\section{DISCLAIMER}

This report was prepared as an account of work sponsored by an agency of the United States Government. Neither the United States Government nor any agency Thereof, nor any of their employees, makes any warranty, express or implied, or assumes any legal liability or responsibility for the accuracy, completeness, or usefulness of any information, apparatus, product, or process disclosed, or represents that its use would not infringe privately owned rights. Reference herein to any specific commercial product, process, or service by trade name, trademark, manufacturer, or otherwise does not necessarily constitute or imply its endorsement, recommendation, or favoring by the United States Government or any agency thereof. The views and opinions of authors expressed herein do not necessarily state or reflect those of the United States Government or any agency thereof. 


\section{DISCLAIMER}

Portions of this document may be illegible in electronic image products. Images are produced from the best available original document. 


\begin{abstract}
This study presents a preliminary evaluation of the technical and economic feasibility of selected conceptual processes for pyrolytic conversion of organic feedstocks or the decomposition/detoxification of hazardous wastes by coupling the process to the geopressured-geothermal resource. The report presents a detailed discussion of the resource and of each process selected for evaluation including the technical evaluation of each. A separate section presents the economic methodology used and the evaluation of the technically viable process. A final section presents conclusions and recommendations. Three separate processes were selected for evaluation. These are pyrolytic conversion of biomass to petroleum like fluids, wet air oxidation (WAO) at subcritical conditions for destruction of hazardous waste, and supercritical water oxidation (SCWO) also for the destruction of hazardous waste. The scientific feasibility of all three processes has been previously established by various bench-scale and pilot-scale studies.
\end{abstract}

For a variety of reasons detailed in the report the SCWO process is the only one deemed to be technically feasible, although the effects of the high solids content of the geothermal brine need further study. This technology shows tremendous promise for contributing to solving the nation's energy and hazardous waste problems. However, the current economic analysis suggests that it is uneconomical at this time, primarily because of uncertainties in the technical, capital cost, and operating parameters necessitating conservative economics assumptions in the analysis. Further effort is refining requirements for design and operation of this process is recommended. 



\section{EXECUTIVE SUMMARY}

This study presents a preliminary evaluation of the technical and economic feasibility of selected conceptual processes for pyrolytic conversion of organic feedstocks or the decomposition/detoxification of hazardous wastes by coupling the process to the geopressured-geothermal resource. Included is a brief introduction to the topic of supercritical fluids and specific discussion of the properties of supercritical water. other sections of the report present a detailed discussion of the resource and of each of the processes selected for evaluation, including the technical evaluation of each. A separate section presents the economic methodology used and the evaluation of the technically viable process. A final section presents conclusions and recommendations.

Three separate processes were selected for evaluation. These are pyrolytic conversion of biomass to petroleum like fluids, wet air oxidation (WAO) at subcritical conditions for destruction of hazardous waste, and supercritical water oxidation (SCWO) also for the destruction of hazardous waste. The scientific feasibility of all three processes has been previously established by various bench-scale and pilot-scale studies. Development of WAO is not considered feasible because of technical limitations related to long reactor residence times and unacceptable destruction efficiencies, typically in the range of only 50 to $95 \%$. Development of pyrolitic conversion is not considered technically or economically feasible because of 1 imitations related to long reactor residence times and difficulties in feeding some feedstocks that significantly limit throughput. In addition, there are other economic disadvantages because the product of such a process is typically a complex mixture requiring significant further processing before an economic product is obtained.

The potential major advantages of the SCWO process as a technology for disposing of hazardous waste compared to current technologies are presented. The SCWO process is deemed to be technically feasible, al though the effects of the high solids content of the geothermal brine need further study. At steady state operating conditions, the SCWO 
process is self-sustaining, producing excess energy that can potentially be recovered in the form of heat and electricity. This technology shows tremendous promise for contributing to solving the nation's energy and hazardous waste problems. However, the current economic analysis suggests that it is uneconomical at this time, primarily because of uncertainties in the technical, capital cost, and operating parameters necessitating conservative economic assumptions in the analysis. Further effort in refining requirements for design and operation of this process is recommended. 


\section{ACKNOWLEDGMENT}

Work supported by the U.S. Department of Energy, Assistant Secretary for Conservation and Renewable Energy Office of Utility Technologies, Under DOE Contract No. DE-AC07-76ID01570. 



\section{CONTENTS}

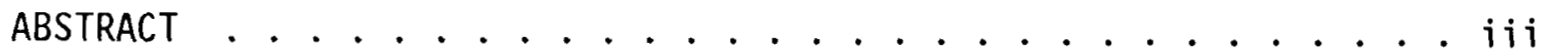

EXECUTIVE SUMMARY . . . . . . . . . . . . . . . . . . . . v

ACKNOWLEDGEMENT . . . . . . . . . . . . . . . . . . . . . vii

CONTENTS . . . . . . . . . . . . . . . . . . . . ix

INTRODUCTION . . . . . . . . . . . . . . . . . . . . . . . 1

Background . . . . . . . . . . . . . . . . . . . . 2

Properties of Supercritical Water... . . . . . . . . 7

Brief Description of Resource . . . . . . . . . . . . . 15

General Discussion of Processing Potential . . . . . . . 17

Pyrolytic Conversion . . . . . . . . . . . . . . 17

Supercritical Water Oxidation (SCWO) . . . . . . . . . 18

Approach ........................ 22

Other High Temperature/High Pressure Processes . . . . 21

PYROLYTIC CONVERSION PROCESS . . . . . . . . . . . . . . 25

Background . . . . . . . . . . . . . . . . . 25

Pyrolytic Conversion Process Discussion . . . . . . . . . 27

Feedstock Selection . . . . . . . . . . . . . . . 27

Technical Evaluation .................... 29

DECOMPOSITION/DETOXIFICATION PROCESS . . . . . . . . . . . 31

Generic Process Description ................ . 31

Discussion of Process Specifics... . . . . . . . . . . 41

Technical Evaluation ................... 47

ECONOMIC EVALUATION ...................... 53

Economic Methodology .................. 53

Determining the Discount Rate........... . . 54

Breakeven Price .. . . . . . . . . . . . . . 55

Discounted Payback Analysis... . . . . . . . . 56

Net Present Value ... . . . . . . . . . . . 56

Economic Assumptions ... . . . . . . . . . . . . . . 57

Financial and Economic Variables . . . . . . . . . 57

Preoperational Variables ............. . 61

Operational Variables ............... 64

Postoperational Variables . . . . . . . . . . . 66

Model Summary . . . . . . . . . . . . . . . . 67

Economic Results ................... 68

CONCLUSIONS/RECOMMENDATIONS . . . . . . . . . . . . . . . 70

Conclusions . . . . . . . . . . . . . . . . . 70

Wet Air Oxidation . . . . . . . . . . . . 70

Pyrolytic Conversion . . . . . . . . . . . . . 70

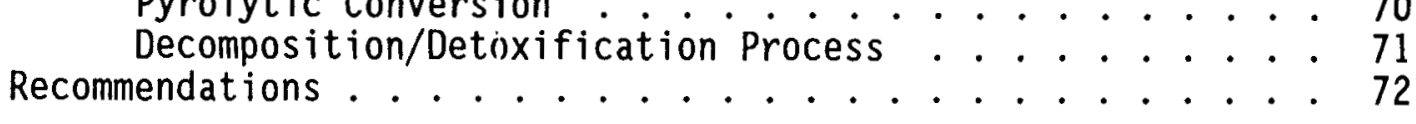

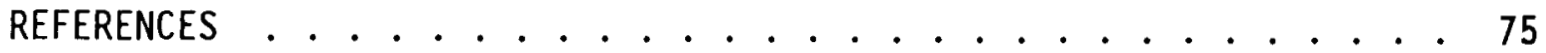


APPENDIX A--Results of Economic Analysis . . . . . . . . . A-1 APPENDIX B--Conversion Table ................. B-1

\section{FIGURES}

1. Fluid density as a function of temperature and pressure ..... 4

2. Phase diagram for water .............. 8

3. Temperature-density diagram for water with isobars and constant dielectric constant lines . . . . . . . . . . . . . . 9

4. Properties of water at 250 ATM . . . . . . . . . . 13

5. Conceptual Process Flow Diagram: Decomposition/Detoxification Process for 100,000 GPD . . . . . . . . . . . 45

\section{TABLES}

1. Comparison of selected fluid properties . . . . . . . . . . 4

2. Resource description ................. 16

3. Substances treated by supercritical water oxidation (SCWO) . . 37

4 Process parameters for SCWO . . . . . . . . . . . . . 44

5. Energy balance for a 100,000 GPD processing plant utilizing air as the oxidizing medium.............. 49

6. Energy balance for a 100,000 GPD processing plant utilizing $99 \%$ oxygen as the oxidizing medium ........... 50

7. Breakeven cost for three selected levels of uncertainty . . . 69 


\section{FEASIBILITY STUDY: \\ APPLICATION OF THE GEOPRESSURED-GEOTHERMAL \\ RESOURCE TO PYROLYTIC CONVERSION \\ OR DECOMPOSITION/DETOXIFICATION PROCESSES}

\section{INTRODUCTION}

A goal of the Department of Energy (DOE) is to provide energy research and development and utilization of stable, long-term, domestic energy. One area of research is the development of the geopressuredgeothermal energy resource. In recent years, the DOE has been sponsoring the Geopressured-Geothermal Research Program and three DOE well operations under the direction of the Idaho National Engineering Laboratory (INEL) to assess and evaluate the technical and production characteristics of this undeveloped resource. The current direction of the Geopressured-Geothermal Program includes investigating various process heat applications of the resource.

This study presents an evaluation of the technical and economic feasibility of conceptual processes for pyrolytic conversion of organic feedstocks or the decomposition/detoxification of hazardous wastes by applying the geopressured-geothermal resource.

Included in the introduction is a background introducing supercritical fluids followed by a brief discussion of the properties of supercritical water. Also included is a brief description of the resource, a general discussion of various high temperature/high pressure processes considered for potential coupling to the resource, and, finally, the approach used in the study.

Following sections present detailed discussion of the resource and each of the processes selected for evaluation, including the technical evaluation of each. The economic evaluation is presented in a separate section. Finally, there is a section presenting conclusions and recommendations. 


\section{BACKGROUND}

In the case of hazardous waste destruction, the conceptual process would be conducted under supercritical fluid (SCF) conditions, where an SCF is defined as one that has been raised simultaneously above both its critical temperature and critical pressure. In this region a single homogeneous phase exists; the fluid exists essentially as a very dense gas.

The initial impetus for the development of SCF technology was because of the potential as a viable separations technique. This interest was fueled by four considerations:

1. There has been a sharp increase in the cost of energy that has increased the cost of traditional, energy-intensive separations processes, such as distillation.

2. There has been increased concern about the health and environmental hazards associated with common industrial organic solvents, such as chlorinated hydrocarbons. This concern has led to increased governmental regulation and scrutiny which, in turn, has fostered development of safer, more environmentally acceptable solvents.

3. In addition, there has been increasingly more stringent legislation regarding pollution control causing consideration of alternative means of waste treatment.

4. Finally, higher performance demands on materials have not been capable of being met by conventional processing techniques. 
In general, SCFs have physical properties that are intermediate between those of a gas and a typical organic liquid, as shown in Table 1. Because of these properties, SCFs have potential as solvents in advanced separations and processing operations. As solvents, they have advantages over either gases or liquids in similar applications. The high diffusivity of SCFs compared to organic liquids provides high mass transfer rates, eliminating diffusion rates and mass transfer as limiting process steps. Thus, process kinetics are typically faster in SCFs than in liquid solvents. The low viscosity and zero surface tension of SCFs give them capabilities for wetting and small pore penetration comparable to those of gases and significantly better than those of liquids. This capability of SCFs can be used to advantage in processes where solid surface-fluid interactions are important, such as solubilization and extraction of constituents from solid matrices.

To a first order, at least, solubility of a solute is a direct function of solvent density; the higher the density, the higher the solubility of the solute. From Table 1 , it is seen that the density of a typical SCF is comparable to that of an organic liquid and is two to three orders of magnitude higher than that of a typical gas.

Correspondingly, the solubilities of typical solutes in SCFs are significantly higher than the solubilities for the same solutes in gases, and the solubilities are comparable to those observed in organic liquid solvents. In addition to having solvent properties similar to liquids, SCFs exhibit the unique property of having densities that are sensitive functions of temperature and pressure, particularly in the region close to the critical point, as shown in Figure 1. This property allows selective solubilization of solutes by means of relatively small changes in the macroscopic system properties of temperature or pressure or both. Similar control of solubility is not possible with either liquids or gases. This solvent property of SCFs is very attractive for applications involving selective solubilization and separation. 
Table 1. Comparison of selected fluid properties.

\begin{tabular}{||l|c|c|c|c||}
\hline Material & Diffusivity & Viscosity & $\begin{array}{l}\text { Surface } \\
\text { Tension }\end{array}$ & Density \\
\cline { 2 - 5 } & $\mathrm{cm}^{2} / \mathrm{s}$ & $\mathrm{cp}$ & dynes $/ \mathrm{cm}$ & $\mathrm{g} / \mathrm{cm}^{3}$ \\
\hline Gas & $10^{-1}$ & $10^{-2}-10^{-3}$ & 0 & $10^{-3}$ \\
Supercritical Fluid & $10^{-3}$ & $10^{-2}$ & 0 & $0.6-1.0$ \\
Organic Liquid & $10^{-5}$ & $10^{-1}$ & $30-60$ & $0.7-1.4$ \\
\hline
\end{tabular}

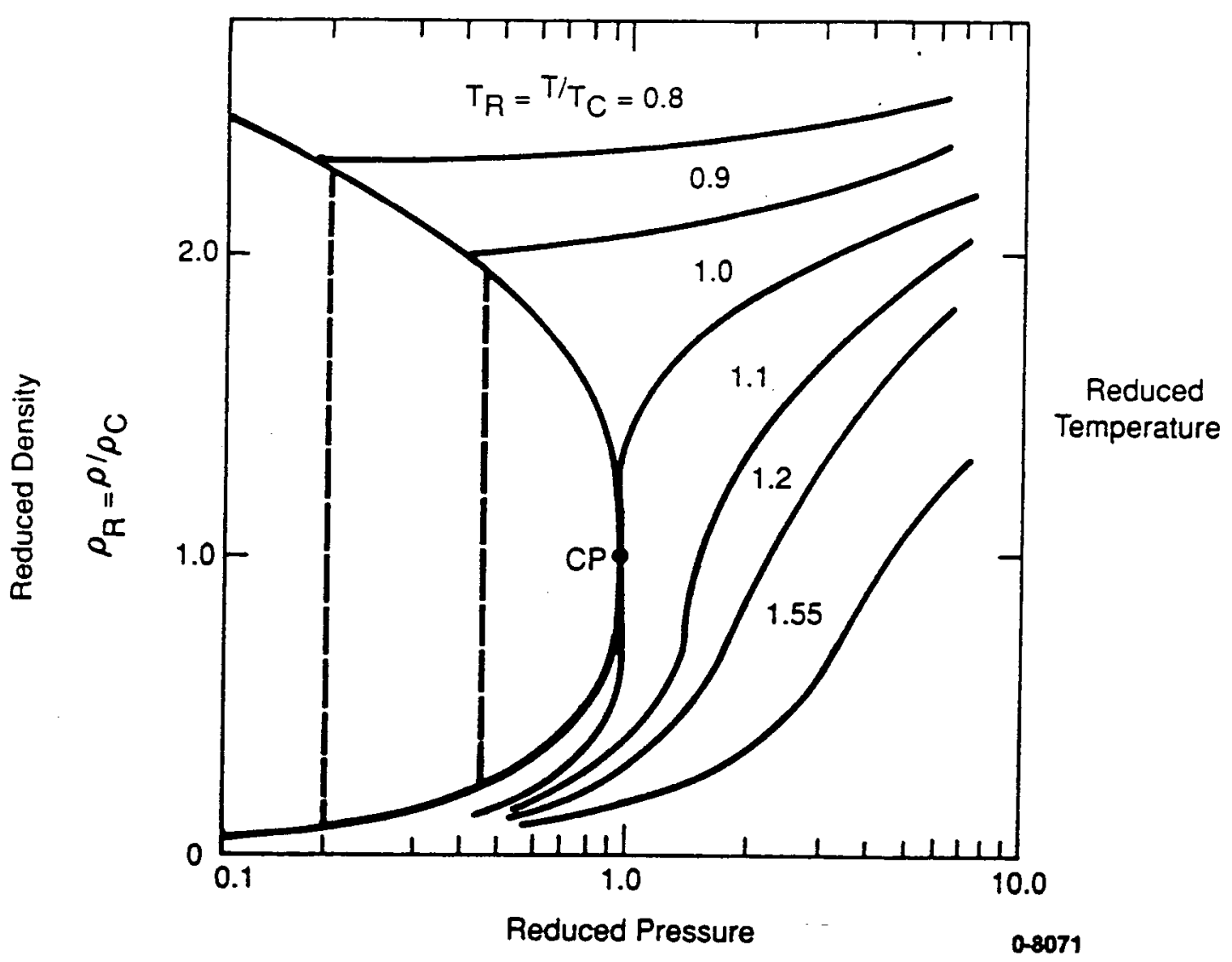

Figure 1. Fluid density as a function of temperature and pressure. 
Several books have been written discussing various aspects of SCF technology, ranging from the basic chemistry and thermodynamics of such systems to discussions of specific process applications and summaries of current research in the area (Schneider et al., 1980; Paulaitis et a1., 1983; Penniger et a1., 1985; Squires and Paulaitis, 1987; McHugh and Krukonis, 1986; Charpentier and Sevenants, 1988; and Johnston and Penninger, 1989).

Much of the initial effort to commercialize SCF technology occurred in Europe in the 1970s (Schneider et al., 1980). The fluid used in the majority of the early applications was carbon dioxide because supercritical conditions are achieved at moderate conditions, i.e., $31^{\circ} \mathrm{C}$ $\left(88^{\circ} \mathrm{F}\right)$ and $72.9 \mathrm{~atm}$ (1072 psia or $\left.7.39 \mathrm{MPa}\right)$; it is nontoxic; has negligible environmental impact; is readily available; and is inexpensive. Other fluids studied included a variety of low molecular weight organics, water, and other inorganics, such as ammonia and nitrous oxide. Equipment design restrictions limited initial applications to batch operations, which restricted process throughput. This limitation coupled with the high capital equipment costs associated with the requirements for high pressure operation means that, for all practical purposes, successful commercial applications of SCFs to date have met the following five criteria:

1. A relatively low volume feedstock is processed.

2. The recovered product has a high unit value.

3. There are significant health or environmental issues associated with the use of alternative solvents.

4. Use of SCFs results in improved process efficiency or reduced overall costs.

5. There is no viable alternative process available.

As can be expected from consideration of the above criteria, many of the significant initial applications of SCF technology have been in the 
food processing, pharmaceutical, and related industries. Specific examples include extraction and recovery of the flavor components from hops, extraction of nicotine from tobacco, and extraction and recovery of chemotherapeutic agents from biological materials. Another area of SCF technology that is currently receiving significant attention is the application to analytical chemistry, both for chromatography in the form of supercritical fluid chromatography and for sample preparation in the form of supercritical fluid extraction used to remove and recover organic analytes from complex matrices. 


\section{Properties of Supercritical Water}

As defined previously, an SCF is one that has been raised simultaneously above both its critical temperature and critical pressure. The critical point for pure water is $374.1^{\circ} \mathrm{C}\left(705.4^{\circ} \mathrm{F}\right)$ and $218.3 \mathrm{~atm}$ (3208 psia or $22.12 \mathrm{MPa}$ ). The supercritical fluid region is identified in Figure 2, schematic temperature-pressure phase diagram for water where $C P$ is the critical point. In this region, water exists as a single homogeneous phase that is essentially a dense gas.

Above its critical point, the properties of water are markedly different from those of liquid water at ambient conditions or those of low pressure steam. For example, organic compounds are completely miscible in water under certain supercritical conditions, while inorganic salts become almost insoluble under other supercritical conditions. As discussed previously for the case of SCFs in general, these solubility characteristics are strongly dependent upon fluid density.

To obtain insight into the solvent behavior of water, reference is made to the temperature-density diagram shown in Figure 3 (Thomason and Model1, 1984). The critical point (CP) at $374.1^{\circ} \mathrm{C}\left(705.4^{\circ} \mathrm{F}\right)$, which lies on the vapor-1iquid saturation dome, occurs at a fluid density of $0.3 \mathrm{~g} / \mathrm{cm}^{3}\left(19 \mathrm{lb} / \mathrm{ft}^{3}\right)$. In this diagram the supercritical region lies above $374.1^{\circ} \mathrm{C}\left(705.4^{\circ} \mathrm{F}\right)$ and to the right of the $220 \mathrm{~atm}(3,230$ psia or $22.3 \mathrm{MPa})$ isobar. Near the critical point, e.g., that region encompassing temperatures between 300 and $450^{\circ} \mathrm{C}\left(572\right.$ and $\left.842^{\circ} \mathrm{F}\right)$ and fluid densities in the range from 0.2 to $0.7 \mathrm{~g} / \mathrm{cm}^{3}\left(12\right.$ to $\left.44 \mathrm{lb} / \mathrm{ft}^{3}\right)$, the fluid density is a sensitive function of temperature, varying rapidly with relatively small changes in temperature at constant pressure. This behavior is consistent with that discussed previously in connection with Figure 1. 


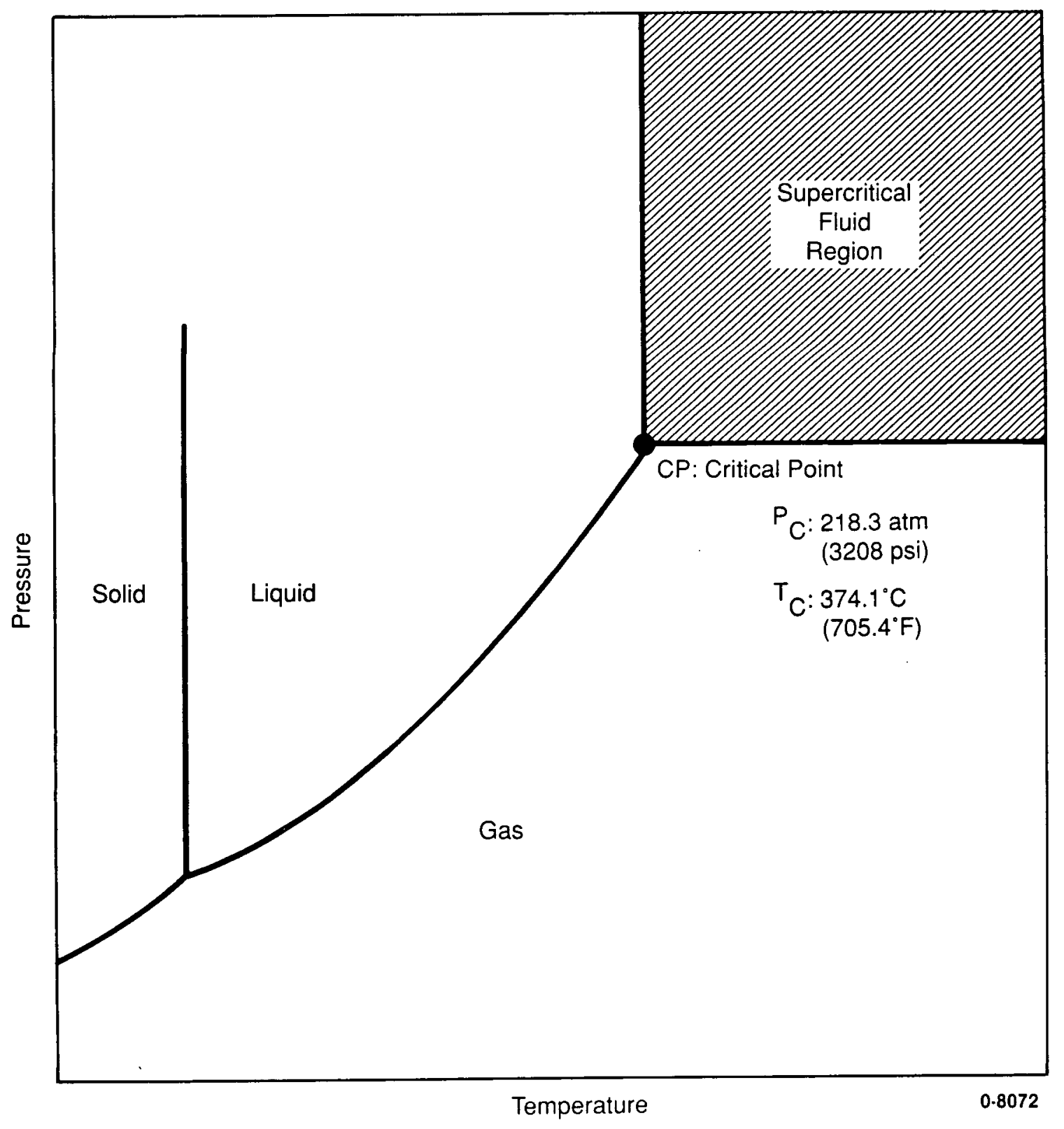

Figure 2: Phase diagram for water. 


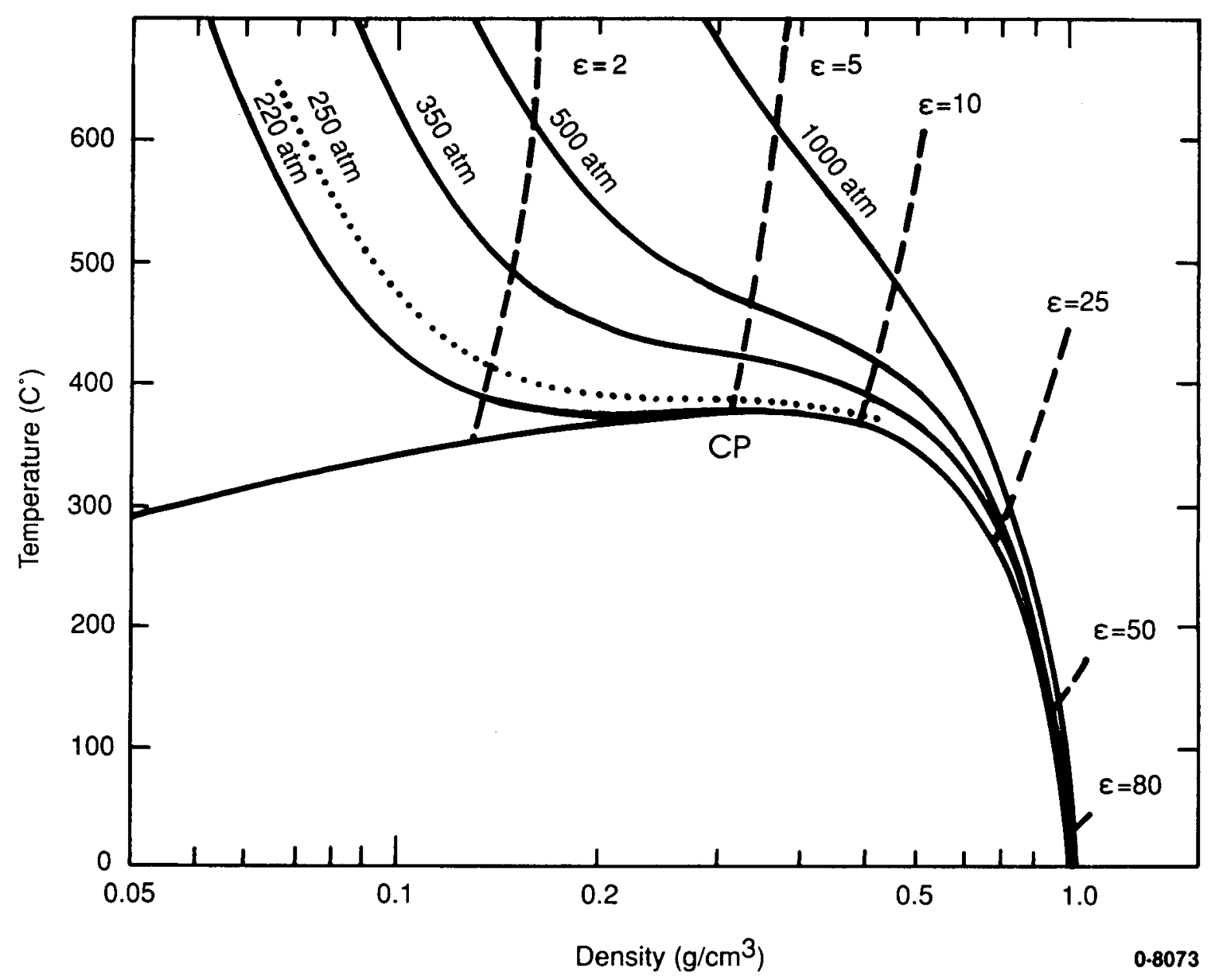

Figure 3: Temperature-density diagram for water with isobars and constant dielectric constant lines. 
Measurements of the static dielectric constant of water in this region have provided insight into the structure of the fluid (Quist and Marsha11, 1965; Uematsu and Franck, 1980). The static dielectric constant, $\epsilon$, as a function of temperature and fluid density is also shown in Figure 3. For water the dielectric constant is a measure of the degree of molecular association, i.e., hydrogen bonding. At ambient conditions liquid water has a dielectric constant of 80 , which is indicative of the strong hydrogen bonding and the polarity of the molecule. For the saturated liquid, the dielectric constant decreases rapidly with increasing temperature, even though the decrease in density with increasing temperature is much slower. This behavior can be explained by the short-range nature of the polarization forces responsible for hydrogen bonding. Because these forces are strong only when the molecules are in close proximity, the changes in intermolecular distances associated with small decreases in density produce significant weakening of hydrogen bonding. In turn, the change in hydrogen bonding produces parallel, relatively large decreases in short-range order resulting in a rapid decline in dielectric constant. For example, at $130^{\circ} \mathrm{C}\left(266^{\circ} \mathrm{F}\right)$ and density $=0.8 \mathrm{~g} / \mathrm{cm}^{3}\left(50 \mathrm{lb} / \mathrm{ft}^{3}\right)$ it has decreased to 25 , which is comparable to that of ethanol.

From Figure 3 it can be seen that as density decreases further, the dielectric constant becomes less temperature dependent, with the lines of constant $\epsilon$ becoming nearly vertical. At the critical point the dielectric constant is 5 , which lies between that of ethyl ether and that of ethyl acetate. Raman spectra of deuterated water in this region indicate negligible residual hydrogen bonding (Franck, 1976). The major contributions to the dielectric constant in this region are produced by the dipole moment of the water molecules and molecular association from dipole-dipole interactions. Further temperature increases reduce the latter contribution further as the void volume increases, resulting in a continual decrease in density. 
Over the $200^{\circ} \mathrm{C}\left(392^{\circ} \mathrm{F}\right)$ temperature change from 300 to $500^{\circ} \mathrm{C}(572$ to $932^{\circ} \mathrm{F}$ ) the dielectric constant of water changes from a value comparable to that of moderately polar to that of nonpolar organic solvents. Although the dielectric constant is not the only factor determining solubility behavior, its variation is consistent with the solvent power of water for organics. The solubility of benzene in water is a good example (Connelly, 1966). At $25^{\circ} \mathrm{C}\left(77^{\circ} \mathrm{F}\right)$ benzene is only sparingly soluble in water at $0.07 \mathrm{wt} \%$. At $260^{\circ} \mathrm{C}\left(500^{\circ} \mathrm{F}\right)$ the solubility has increased to about $8 \mathrm{wt} \%$ and is relatively insensitive to pressure. By $287^{\circ} \mathrm{C}\left(549^{\circ} \mathrm{F}\right)$, the solubility is somewhat pressure dependent, with a maximum of $28 \mathrm{wt} \%$ in the pressure range 200 to $250 \mathrm{~atm}$ ( 2940 to 3670 psia or 20.3 to $25.3 \mathrm{MPa}$ ). In the same pressure range the solubility increases to $35 \mathrm{wt} \%$ at $295^{\circ} \mathrm{C}\left(563^{\circ} \mathrm{F}\right)$, and at $300^{\circ} \mathrm{C}\left(572^{\circ} \mathrm{F}\right)$ the critical point of the benzene-water system is reached with the components becoming completely miscible. Other hydrocarbons exhibit similar solubility behavior, although aliphatic hydrocarbons are somewhat less soluble than benzene at comparable temperatures.

The solubility behavior for inorganic salts in water is as unusual as that for organics at fluid densities less than $0.7 \mathrm{~g} / \mathrm{cm}^{3}\left(44 \mathrm{lb} / \mathrm{ft}^{3}\right)$. For a pressure of $250 \mathrm{~atm}$ ( 3670 psia or $25.3 \mathrm{MPa}$ ), the solubilities of inorganic salts reach a maximum in the temperature range from 300 to $450^{\circ} \mathrm{C}\left(572\right.$ to $\left.842^{\circ} \mathrm{F}\right)$. Then beyond the maximum, the solubilities decrease sharply with increasing temperature. As an example, the solubility of sodium chloride is about $40 \mathrm{wt} \%$ at $300^{\circ} \mathrm{C}\left(572^{\circ} \mathrm{F}\right)$, decreasing rapidly to only $100 \mathrm{ppm}$ at $450^{\circ} \mathrm{C}\left(842^{\circ} \mathrm{F}\right)$ (Pitzer and Pabalan, 1986). Similarly, calcium chloride reaches a maximum solubility of $70 \mathrm{wt} \%$ at subcritical temperatures then dropping to only $10 \mathrm{ppm}$ at $500^{\circ} \mathrm{C}\left(932^{\circ} \mathrm{F}\right.$ ) (Martynova, 1976). This pattern for the solubility of inorganics is consistent with changes in the dielectric constant for water, which has fallen to around 2 at $490^{\circ} \mathrm{C}\left(914^{\circ} \mathrm{F}\right)$ and $250 \mathrm{~atm}(3670 \mathrm{psia}$ or $25.3 \mathrm{MPa})$. 
As a corollary to its loss of solvent power for inorganic salts, water also loses the capacity to dissociate salts as it passes to the supercritical phase. As an example, the dissociation constant for sodium chloride at temperatures around $450^{\circ} \mathrm{C}\left(842^{\circ} \mathrm{F}\right)$ and fluid densities of about $0.35 \mathrm{~g} / \mathrm{cm}^{3}\left(22 \mathrm{lb} / \mathrm{ft}^{3}\right.$ ) is only on the order of $10^{-4}$ (Pitzer and Pabalan, 1986). This illustrates the fact that compounds that are strong electrolytes in water at ambient conditions become weak electrolytes in supercritical water. This behavior is also consistent with the observed changes in the dielectric constant of water.

The properties of water discussed above are summarized in Figure 4 as a function of temperature (Thomason and Mode11, 1984). As noted previously, water goes through a complete reversal in solvent power for organics and inorganics over the temperature range from 350 to $450^{\circ} \mathrm{C}$ $\left(662\right.$ to $\left.842^{\circ} \mathrm{F}\right)$. Below $350^{\circ} \mathrm{C}\left(662^{\circ} \mathrm{F}\right)$ the solubility behavior is similar to that of water at ambient conditions with low solubility for organics and high solubility for inorganics. Above $450^{\circ} \mathrm{C}\left(842^{\circ} \mathrm{F}\right)$ the behavior is reversed with high solubility for organics and very low solubility for inorganics. Within the temperature range, both classes of compounds are relatively soluble. In addition to its solvent properties, supercritical water also exhibits the surface tension, viscosity, and diffusivity behavior typical of such a fluid. This makes possible rapid mixing of constituents in a single homogeneous phase Figure 4 without use of mechanical stirring or agitation. Furthermore, reaction kinetics are not diffusion limited so reactions proceed more rapidly. 


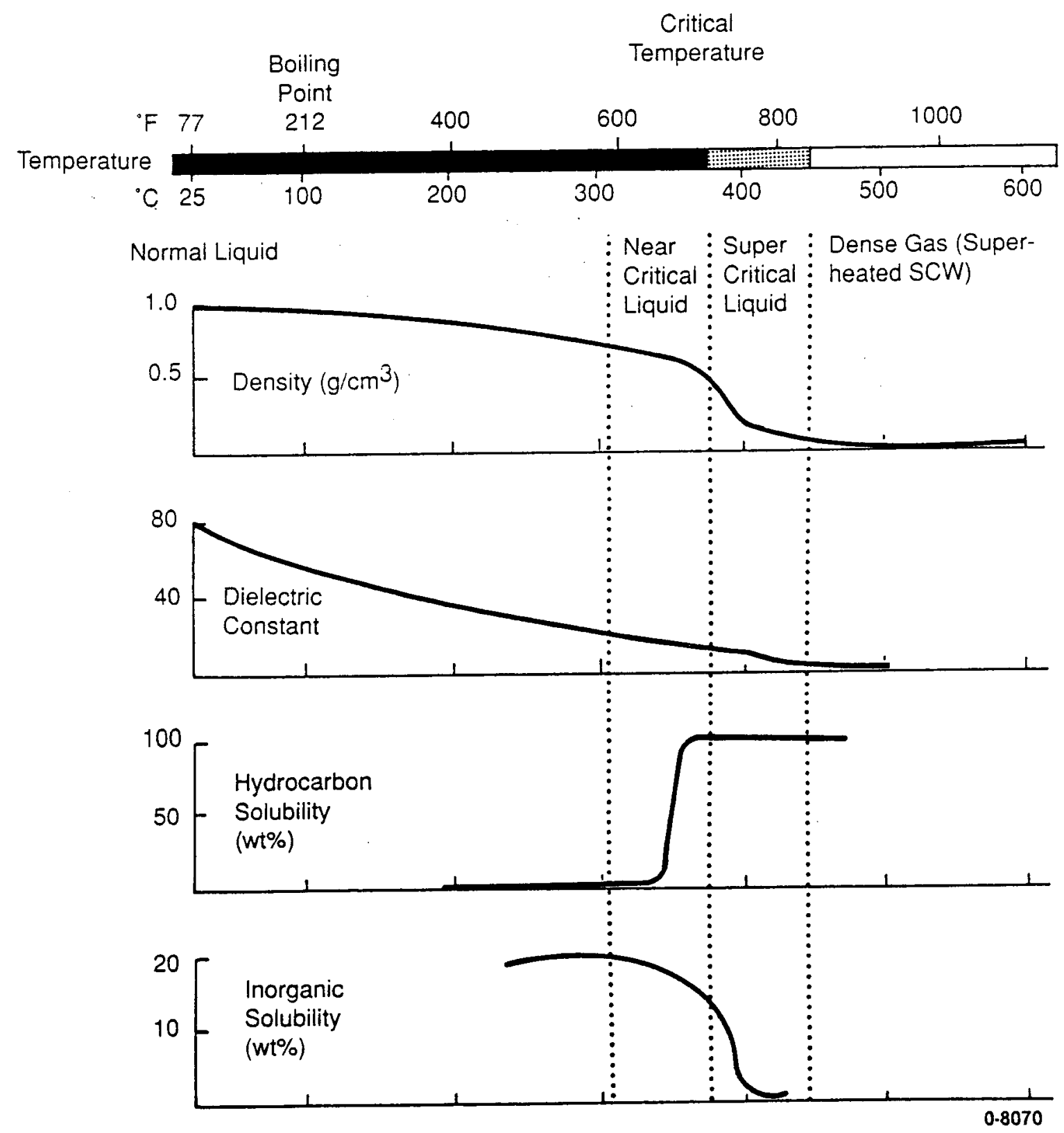

Figure 4: Properties of water at 250 ATM. 


\section{Brief Description of Resource}

The objective of this study is to investigate the utilization of the geopressured-geothermal resource as the energy source for conceptual processes for either pyrolytic conversion of organic feedstocks or the decomposition/detoxification of hazardous wastes. Thus, a brief description of the resource follows by way of introduction.

The geopressured-geothermal resource has an estimated 5700 quadrillion Btus (quads) $\left(6.0 \times 10^{21} \mathrm{~J}\right)$ of gas and 11,000 quads $\left(12 \times 10^{21}\right)$ of recoverable energy in the onshore Texas and Louisiana Gulf Coast area alone. This large energy potential provides the impetus for coupling the resource to processes such as the ones conceptualized in this report. These resources have three energy forms: thermal, hydraulic, and chemical (methane gas), all of which could be utilized in the proposed processes.

Currently, three wells have been identified as possible sources to be used in future site demonstrations of the processes. These are the Gladys McCall We11 in Cameron Parish, Louisiana; the Pleasant Bayou Well in Brazoria County, Texas; and the Hulin Well in Vermilion Parish, Louisiana. The Gladys McCall is shut-in and is being monitored for pressure buildup. A 1 MWe (1340 hp) hybrid power system was constructed and is in operation at the Pleasant Bayou We11. The Hul in Well has been short-term flow tested after being reworked. It is currently shut-in.

Table 2 provides a summary of well characteristics taken from Negus-de Wys and Dorfman (1990). The data have been adapted by converting units as appropriate for the proposed processes. The maximum flow rates range from $438 \mathrm{gpm}(33.2 \mathrm{~L} / \mathrm{s})$ for Hul in to $1167 \mathrm{gpm}$ $(88.42 \mathrm{~L} / \mathrm{s})$ for Gladys McCal1. The flowing wellhead pressures and temperatures range from $2000 \mathrm{psia}(13.8 \mathrm{MPa})$ at $268^{\circ} \mathrm{F}\left(131^{\circ} \mathrm{C}\right)$ for Gladys McCall to 3500 psia $(24.1 \mathrm{MPa})$ at $330^{\circ} \mathrm{F}\left(166^{\circ} \mathrm{C}\right)$ for Hulin. Finally, the 
total dissolved solids (TDS) content of the brine ranges from $95,000 \mathrm{mg} / \mathrm{L}$ (0.79 1b/gal) for Gladys McCall to $195,000 \mathrm{mg} / \mathrm{L}(1.63 \mathrm{lb} / \mathrm{gal})$ for Hulin. More details of the resource properties will be provided in a later section.

Table 2. Resource description.

\begin{tabular}{|c|c|c|c|}
\hline & $\begin{array}{l}\text { Gladys } \\
\text { McCall }\end{array}$ & $\begin{array}{l}\text { Pleasant } \\
\text { Bayou }\end{array}$ & Hul in \\
\hline $\begin{array}{l}\text { Maximum Flow Rate } \\
(\mathrm{gpm})\end{array}$ & 1167 & 729 & 438 \\
\hline $\begin{array}{l}\text { Flowing Wellhead } \\
\text { Pressure (psia) }\end{array}$ & 2000 & 3000 & 3500 \\
\hline $\begin{array}{l}\text { Bottomhole Temperature } \\
\left({ }^{\circ} \mathrm{F}\right)\end{array}$ & 298 & 302 & 360 \\
\hline $\begin{array}{l}\text { Flowing Wellhead } \\
\left.\text { Temperature ( }{ }^{\circ} \mathrm{F}\right)\end{array}$ & 268 & 292 & 330 \\
\hline $\begin{array}{l}\text { Gas/Water Ratio } \\
\text { (scf/gal) }\end{array}$ & 0.64 & 0.57 & 0.81 \\
\hline Methane (\% of Gas) & 85 & 85 & 93 \\
\hline $\mathrm{CO}_{2}$ (\% of Gas) & 9.7 & 10 & 4 \\
\hline $\begin{array}{l}\text { Estimated Reservoir } \\
\text { Size (billion gal) }\end{array}$ & 168 & 336 & 588 \\
\hline $\begin{array}{l}\text { Total Dissolved solids } \\
(\mathrm{mg} / \mathrm{L})\end{array}$ & 95,000 & 127,000 & 195,000 \\
\hline Total chlorides (mg/L) & 57,000 & 70,000 & 115,000 \\
\hline
\end{tabular}




\section{General Discussion of Processing Potential}

A brief discussion of each of the selected processes is presented below followed by a discussion of other high temperature/high pressure treatment alternatives.

\section{Pyrolytic Conversion}

Pyrolysis of organic wastes could provide two benefits: (a) the reduction of organic waste, and (b) the formation of hydrocarbon compounds.

$0 i 1$ company laboratories have worked with pyrolysis for the past 15 years with Shell 0il, Exxon, Chevron, and Amoco being among the pioneers in this field. The natural feedstocks for hydrocarbon source materials are marine and terrestrial organic material (kerogen).

With geological time and temperature these source materials are converted to $0 i 1$ and gas. The ingredients are basically "cooked" under pressure. Thus, in proprietary oil company laboratories researchers use high pressure autoclaves, first replicating closed systems, and more recently, semi-open systems.

Studies By Dr. B. R. T. Simoneit of Oregon State University at hydrothermal vents along ocean spreading centers indicated essentially instantaneous conversion of the microbial detritus in the marine sediment to petroleum-like products. This represents an elimination of time in the time/temperature index traditionally applied to hydrocarbon formation (Simoneit and Lonsdale, 1982; Simoneit, 1983; Simoneit, 1984a; 1984b; Simoneit et al., 1984c; Simoneit and Galimov, 1984d; Simoneit 1985a; 1985b).

Preliminary pyrolysis studies have been successfully conducted at the INEL using several different feedstocks and fluid compositions. The feedstocks included kelp, refuse derived fuel (RDF) obtained as the combustible fraction of municipal solid waste and organic sludge. The fluids 
studied consisted of aqueous media of various compositions. Operating conditions studied ranged up to about $370^{\circ} \mathrm{C}\left(698^{\circ} \mathrm{F}\right)$ and $217.8 \mathrm{~atm}(3200 \mathrm{psia}$ or $22.07 \mathrm{MPa}$ ), very close to supercritical water conditions. The products formed ranged from normal alkanes to polynuclear aromatics, ketones, carboxylic acids, phenolics and nitrogen and sulfur containing hetrocompounds, depending on feedstock and experimental conditions.

In the proposed application, processing would be at geopressuredgeothermal reservoir conditions or above, if higher conditions would be required to promote conversion rates. Higher temperatures and pressures could be achieved by also utilizing the hydraulic and chemical energy in the geopressured resource. One possibility in processing could be either by direct contact with reservoir fluid or by circulating fluid down into the reservoir to generate conditions. Experimental feedstocks previously considered for processing include biomass or derived products such as wood chips, straw, bagasse (residual from cane processing), water hyacinths, agriculture processing residues, cellulose, hemicellulose or lignin, RDF, peat and organic sludge. The specific feedstocks selected would depend upon the goal of the pyrolysis and such variables as availability, cost and processing site location in order to optimize process economics. Similarly, process specifics would depend on reservoir conditions, location and product selection. These details would be finalized during final design to optimize the overall process and economics.

In summary, the pyrolysis process has been included in considering the use of supercritical water in the detoxification of pollutants for three basic reasons: (a) process conditions for pyrolysis can be similar to supercritical conditions, (b) it addresses two concerns, reduction of waste and development of hydrocarbons and (c) pyrolysis may be more compatible with the geopressured resource as a process to utilize the resource.

\section{Supercritical Water Oxidation (SCWO)}

Supercritical water destruction of hazardous organic wastes could provide five major benefits: (a) the reduction of organic waste, (b) the potential for high destruction efficiencies, (c) the production of clean effluents 
containing no hazardous constituents, (d) a readily available means for disposing of inorganic products formed during the destruction and (e) applicability to a wide variety of wastes.

Use of supercritical water for destruction of organic wastes has been studied for the past 15 years. M. Mode 11 and coworkers (Thomason and Mode11, 1984; Whelan et al., 1988) have been pioneers in the area. Other workers have included Rofer and G. Streit (Rofer, 1987 and 1990; Rofer and Streit, 1989) and W. Killilea and collaborators (Staszak et al.; Malinowski and Killilea, 1987).

As discussed previously, above its critical point water exhibits properties that make it eminently suitable as a medium for destruction of most organic compounds. The high dielectric constant of liquid water (80), ascribable to the hydrogen bonding present in the liquid, decreases to about 2.5 with the concomitant weakening and disappearance of hydrogen bonding. In addition, there is a corresponding decrease in fluid density from $1 \mathrm{~g} / \mathrm{cm}^{3}$ $\left(62.4 \mathrm{lb} / \mathrm{ft}^{3}\right)$ to about $0.3 \mathrm{~g} / \mathrm{cm}^{3}\left(19 \mathrm{lb} / \mathrm{ft}^{3}\right)$. The net result of these two effects is a pronounced change in the solvent properties of water. As the critical point is approached there is a sharp decrease in solubility of inorganic compounds with a corresponding sharp increase in solubility of organic compounds and nonpolar gases; supercritical water is a poor solvent for inorganics and a good solvent for organics.

In addition to its solvent properties, supercritical water also exhibits the surface tension, viscosity, and diffusivity behavior typical of supercritical fluids. This makes possible rapid mixing of constituents in a single phase without use of mechanical stirring or agitation. Furthermore, reaction kinetics are not diffusion limited.

The proposed process has potential applicability to a wide variety of wastes containing organic constituents. It would be particularly appropriate for aqueous media such as wastewater or groundwater contaminated with organics. In addition, it could be applied to liquids, slurries, sludges, or solids. The latter could be in the form of solid organics or solids contaminated with organics. 
In the proposed application, processing would occur at or above supercritical conditions for water. These conditions are not directly available from the geopressured-geothermal resource. Typical wellhead conditions are about $150^{\circ} \mathrm{C}\left(302^{\circ} \mathrm{F}\right)$ and 204 atm $(3000$ psia or $20.7 \mathrm{MPa})$, corresponding to slightly less than critical pressure but well below critical temperature. The methane or other combustible gas present in the brine would be burned, utilizing the heat released to raise the fluid temperature above the critical point. Waste and compressed air or oxygen would be injected into the supercritical water where the organics would be rapidly oxidized.

Residence times for complete destruction are typically on the order of $1 \mathrm{~min}$ or less. With $2 \%$ or more of combustible waste, the reaction should become self-sustaining. Because of the high rate of the combustion process, operation approaches adiabatic conditions, with heat losses being small. For example, if compressed air is used as the oxidizer and the feed contains about 5 wt\% of organics with an inlet temperature of $400^{\circ} \mathrm{C}\left(752^{\circ} \mathrm{F}\right)$ at about $250 \mathrm{~atm}$ (3670 psia or $25.3 \mathrm{MPa}$ ), fluid outlet temperatures from the reactor on the order of 500 to $600^{\circ} \mathrm{C}\left(932\right.$ to $\left.1110^{\circ} \mathrm{F}\right)$ should be attainable. Temperature at reactor outlet will depend upon specific inlet conditions and concentration of organics in the feed.

Under the operating conditions above, reaction of most organics should be essentially complete, with the primary reaction products being carbon dioxide and water. Although this oxidation is similar to combustion, the formation of nitrogen oxides should be negligible because of the much lower temperatures involved, in contrast to those typical of incineration $\left(1800^{\circ} \mathrm{C} ; 3300^{\circ} \mathrm{F}\right)$. In addition, any inorganics present would precipitate out under these conditions and could be separated out by use of a hydrocyclone, for example.

If necessary, part of the effluent fluid from the process could be recycled for use as the reaction medium to maintain the process. Part of it would be blown down to prevent excess solids buildup in the system. The blowdown could be reinjected into the reservoir, if appropriate, or be cooled to ambient conditions for recovery and disposal of the solids. Energy from the blowdown would be recovered to preheat the makeup fluid from the reservoir. At reactor outlet conditions, after removing precipitated solids, 
the fluid would be a mixture of relatively pure superheated steam and carbon dioxide. A portion of this fluid could be bled off to provide energy for operating the system air compressor turbine, either directly or by heat exchange to another working fluid. Energy from the effluent could also be recovered by heat exchange to preheat the makeup fluid, air and waste. The methane from the makeup brine would be used to provide additional energy.

Process specifics will depend on actual reservoir conditions and waste feed composition. These details would be finalized during detailed process design to optimize the overall process and economics.

In summary, it is expected that application of the geopressuredgeothermal resource to the supercritical water destruction of organic wastes will reduce process energy costs and provide a convenient means of disposing of inorganic constituents from the process.

\section{Other High Temperature/High Pressure Processes}

The only other high temperature/high pressure process comparable to the supercritical water oxidation ( $\mathrm{SCWO}$ ) process being considered is wet air oxidation (WAO). In point of fact, it will be seen that SCWO is actually an extension of the WAO process to higher temperatures and pressures to capitalize on the advantages of operating at SCF conditions. In WAO, organic wastes are oxidized in the aqueous phase under pressures on the order of $150 \mathrm{~atm}\left(2200 \mathrm{psia}\right.$ or $15.2 \mathrm{MPa}$ ) at temperatures ranging from 150 to $300^{\circ} \mathrm{C}$ (302 to $572^{\circ} \mathrm{F}$ ) (Wilhelmi and Knopp, 1979).

A recent report has presented a fairly detailed evaluation of the application of both WAO and SCWO to the destruction of typical industrial aqueous wastes (Stone and Webster Engineering Corporation, 1989). WAO is applicable for situations involving relatively innocuous wastes where the intent is to reduce chemical oxygen demand (COD) before discharge, e.g., to the sewer, without the need for extremely high destruction removal efficiencies (DREs). However, WAO suffers from several limitations that make it inapplicable to the destruction of the majority of hazardous organic wastes. 
In the first place, under the conditions of operation, the solubility of oxygen in water is significantly less than the stoichiometric amount needed for complete oxidation. Therefore, a two-phase mixture exists in the reactor, producing residence-time requirements ranging from 0.5 to $2 \mathrm{~h}$. Because the reactor not only must operate at high temperatures and pressures but must also be of relatively large volume to meet the residence-time requirements, the associated high cost will have a significant impact on the capital costs for the process.

Secondly, DREs depend not only on operating conditions but also on the relative stability of the constituents of the waste. For WAO, DREs typically range from 50 to $95 \%$ depending upon conditions. The DREs for less stable organics such as nitrotoluenes and nitrobenzenes can be as high as $99.9 \%$; however, for more refractory classes of compounds, such as polychlorinated biphenyls (PCBS), DREs are much lower and would not meet regulatory requirements. Thus, the applicability of WAO is much more restricted compared to the range of wastes treatable by SCWO.

Finally, because WAO does not completely convert the waste constituents to innocuous products, the process effluent streams, including both liquid and off-gas, can contain appreciable levels of organics requiring additional treatment before the effluent streams can be discharged to the environment.

Because of the limitations of the WAO process, it has not been considered for further evaluation in the study.

\section{APPROACH}

Selection of processes for evaluation in this study has been based both on processing potential as well as the applicability of coupling the process to the geopressured-geothermal resource. Thus, the two processes selected, pyrolytic conversion and decomposition/detoxification processes, both have significant processing potential. For these processes, there are a variety of 
abundant feedstocks. Also, the feedstocks are widely enough distributed geographically so that access to the resource will not be restricted. In addition, the processes are such that the energy available in the resource, thermal, hydraulic, and methane gas, can be effectively utilized to at least partially offset process energy requirements.

The resource selected for study consists of the three geopressuredgeothermal wells currently included in the ongoing DOE Geopressured-Geothermal Research Program. These are the Gladys McCall Well in Cameron Parish, Louisiana; the Pleasant Bayou Well in Brazoria County, Texas; and the Hul in Well in Vemilion Parish, Louisiana. Because the brine characteristics of the three wells, which will be discussed in the next section, are similar, composite brine has been utilized for the purposes of this study.

The selected processes have been evaluated on the basis of technical feasibility from both the scientific and engineering level. First, the scientific viability of the respective process has been evaluated to establish operational parameters, limitations, weaknesses, and restrictions, followed by an evaluation of the engineering viability of each process, looking at the same types of information used to evaluate scientific viability. Finally, if the process is evaluated to be technically viable, then an economic evaluation has been performed to determine capital, operating and other costs associated with the process to determine commercial viability. 


\section{PYROLYTIC CONVERSION PROCESS}

This section presents a detailed discussion of the pyrolytic conversion process. Included are a background discussion, a description of the process, a description of the potential feedstocks, and the technical evaluation of the process.

\section{BACKGROUND}

There is excellent potential for pyrolytic conversion of organic material to methane or petroleum-like products utilizing geopressured-geothermal resources. Utilizing these resources is similar to natural processes occuring at thermal vents located along ocean spreading centers. Probably one of the most thoroughly studied hydrothermal vent areas is the Guaymas Basin in the Gulf of California. Work by Dr. B. R. T. Simoneit of Oregon State University has shown essentially instantaneous conversion of organic marine detritus to petroleum products at these hydrothermal vents (Simoneit et al., 1984).

The temperature of water exiting hydrothermal vents is nominally in the range of $350^{\circ} \mathrm{C}\left(662^{\circ} \mathrm{F}\right)$, and because of ocean depth the pressure is about $200 \mathrm{~atm}$ ( $3000 \mathrm{psia}$ or $20.3 \mathrm{MPa}$ ). This compares with the geopressuredgeothermal wells located in the Gulf Coast area. For example, the Hul in Well has a flowing wellhead pressure of about $240 \mathrm{~atm}$ ( $3530 \mathrm{psia}$ or $24.3 \mathrm{MPa}$ ) and a wellhead temperature of about $180^{\circ} \mathrm{C}\left(356^{\circ} \mathrm{F}\right)$. It is possible that external heating may be required to bring the water at the Hul in Well to the desired reaction temperature for pryolytic conversion.

Initial concept studies were performed at the INEL to determine the feasibility of using ocean hydrothermal vents for the conversion of organic matter to petroleum-like products. For these tests a flow-through system was used. This consisted of a sample container that could be pressurized to over $204 \mathrm{~atm}(3000 \mathrm{psia}$ or $20.7 \mathrm{MPa})$ and a heating system to bring the water to 
$350^{\circ} \mathrm{C}\left(662^{\circ} \mathrm{F}\right)$. The heated water was passed through the pressurized sample container at flow rates of $40 \mathrm{~mL} / \mathrm{h}(0.011 \mathrm{gph})$ and $100 \mathrm{~mL} / \mathrm{h}(0.026 \mathrm{gph})$.

One set of runs, using dried sewage sludge as the feedstock, was made at $350^{\circ} \mathrm{C}\left(662^{\circ} \mathrm{F}\right)$ and a flow rate of $100 \mathrm{~mL} / \mathrm{h}(0.026 \mathrm{gph})$. Analysis of the derived products showed that $n$-alkanes ranging from $>C_{14}$ to $C_{34}$ were predominant. There was also a large unresolved complex mixture of naphthenes. Two other runs, one at a higher temperature $\left(365^{\circ} \mathrm{C}\right.$ or $\left.689^{\circ} \mathrm{F}\right)$ and the other at a slower flow rate $(40 \mathrm{~mL} / \mathrm{h}$ or $0.011 \mathrm{gph})$, yielded essentially the same product mix. However, the $n$-alkanes were not significant components and the unresolved peak of naphthenes was reduced. This initial study would indicate that temperatures $\angle 350^{\circ} \mathrm{C}\left(<662^{\circ} \mathrm{F}\right)$ would be desirable for conversion of dried sewage sludge to petroleum-like products.

In addition to the studies at the INEL, other laboratories have investigated the potential of converting renewable resources, coal, and oil shale to petroleum products for over 15 years. One of the first studies was in 1973, at the Naval Weapons Center (Benham and Diebold, 1975). Their feedstock was primarily a cellulosic material derived from municipal solid waste. They took two approaches: (a) pyrolysis of the waste to form reactive hydrocarbons, such as ethylene and propylene, with subsequent conversion to synthetic petroleum and (b) complete pyrolys is to carbon monoxide and hydrogen with subsequent conversion to methanol. Additional studies of these reactions have shown that increasing the moisture content of the municipal solid waste and decreasing the residence time to $<0.5 \mathrm{~s}$ increased the production of these gases (Sanner et a7., 1970; McFarland et al., 1972). Major 017 companies, such as She11, Exxon, and Chevron also have been active in the pyrolysis of organic wastes to form hydrocarbon compounds.

The majority of studies were conducted in a batch system and normally focused on one type of feedstock. It appears from initial studies at the INEL that a flow-through or dynamic system would be equally viable for the conversion of organic matter to petroleum-like products. 


\section{Pyrolytic Conversion Process Discussion}

Laboratory studies to determine the feasibility of using a geopressured-geothermal resource for the pyrolytic conversion of organic feedstocks to petroleum-like products or methane would be performed in a flowthrough or dynamic system. In the system currently available, the temperature can be varied up to about $350^{\circ} \mathrm{C}\left(662^{\circ} \mathrm{F}\right)$ and pressures to over $204 \mathrm{~atm}$ (3000 psia or $20.7 \mathrm{MPa}$ ). Residence times in the reactor can vary from approximately 5 minutes to 6 hours.

Initial tests would be run at temperature and pressure conditions characteristic of a given well. These conditions would then be adjusted depending on the results. If additional heating is required, this could be supplied from the hydrocarbon gases obtained from the well.

It is doubtful if wellhead temperature would be sufficient for complete destruction of hazardous materials. For this particular activity, supercritical water would be preferred. The supercritical concept is covered in the next section.

An additional area of concern is the corrosive effect of the saline liquid obtained from geothermal wells. In the three wells under consideration, the TDS ranges from 95,000 to $195,000 \mathrm{mg} / \mathrm{L}(0.79 \mathrm{lb} / \mathrm{ga} 1$ to $1.63 \mathrm{lb} / \mathrm{ga} 1)$. Corrosion studies would be required for selection of construction materials. In addition, the catalytic effects of any transition metals present in the dissolved solids is an unknown factor. These effects could be ascertained by performing base runs using distilled water, and the same temperature and pressure as used for well water, or simulated well water.

\section{Feedstock Selection}

The selection of a feedstock is governed by several factors. The geothermal wells in question are all located in the Gulf Coast region, (two in Louisiana and one in Texas). The selected feedstock must: (a) be readily 
available in the vicinity of the geothermal well, (b) be available in sufficient quantity to make a pyrolytic process practical, (c) be available in a form that will require a minimum of pretreatment and (d) have an initial composition that can produce the desired end products. Another requirement to be considered is that the residue from any pyrolytic process can be readily disposed of.

Some of the potential feedstocks that fit the above criteria are:

1. Sugar cane bagasse

2. Rice hulls

3. Sewage sludge

Sugar came bagasse and rice hulls are available in large quantities in the Gulf coast area. These two materials are primarily cellulosic and hemicellulosic in nature. Previous work in our laboratory has shown that materials of similar composition (kelp) can be pyrolyzed to light hydrocarbon gases and a petroleum-like liquid. The gases were primarily methane through propane. The liquid portion, while not resolved, contained over 35 components with molecular weights ranging from 50 to 350 amu.

Probably one of the most viable feedstocks is dried sewage sludge. The Gulf Coast, with its high population density, produces an abundant and continuous supply of this raw material. In addition, it is fast becoming a major problem for metropolitan areas to dispose of this material.

Sewage sludge is rich in aliphatic hydrocarbons and relatively low in aromatic components. Therefore, under proper pyrolytic conditions, sewage sludge should be convertible into a petroleum-base product.

Some initial tests in our laboratory on hydrous flow-pyrolysis of dried sewage sludge were performed at $350^{\circ} \mathrm{C}\left(662^{\circ} \mathrm{F}\right)$ and $204 \mathrm{~atm}$ $(3000 \mathrm{psia}$ or $20.7 \mathrm{MPa})$. The resulting product yielded an extract with dominant $n$-alkanes ranging from $>C_{14}$ to $C_{34}$, and a major unresolved complex mixture. The $n$-alkanes exhibited essentially no carbon number predominance analogous to typical petroleum. In addition to the $n$-alkanes, there was a 
complex mixture of organic materials containing stanols and stanones, di- and tri-terpenoids, and various polynuclear aromatic compounds. There was also a large peak for dioctylphthalate. These preliminary studies demonstrated the viability of dried sewage sludge as a feedstock for hydrous pyrolysis systems.

\section{Technical Evaluation}

The significant processing potential represented by various biomass sources and residues suitable as feedstocks for processing by pyrolys is has been established in the preceding discussion on feedstocks. Furthermore, it has been shown that these feedstocks should also be readily available within the vicinity of the resource so that access should present no problem. Therefore, the proposed process is viable with respect to processing potential.

The scientific feasibility has also been addressed in the preceding discussions. However, there are significant engineering limitations to the process. In the first place, char formation is typically a problem in such processes unless a steam reforming or partial oxidization step at high temperatures is included. However, under these conditions, which are endothermic, part of the carbon is oxidized to carbon dioxide. To circumvent this problem, processing under supercritical water conditions has been investigated with scientific feasibility being established (Mode11, 1985). However, this approach still suffers from requiring long residence times ranging from 15 minutes to one hour. Thus, al1 processes of this type have significant throughput limitations. In addition, because of difficulties in feeding many of the feedstock materials, processing can only be accomplished by batch operation, further reducing throughput. Finally, the product of most pyrolysis processes is a complex mixture requiring significant further investment before an economic product can be realized. Even in the case of processing under supercritical water conditions, the product will be a gaseous mixture consisting not only of methane but also high levels of carbon dioxide, carbon monoxide, and hydrogen which would require further processing before use. 
There is also the issue of coupling the process to the geopressuredgeothermal resource. It is not clear that the brine could successfully be used as the processing medium because of the high TDS. Further studies in this area would be required.

Because of the significant limitations discussed above, engineering feasibility of the process has not been established. Therefore, an economic evaluation of this process has not been conducted. 


\section{DECOMPOSITION/DETOXIFICATION PROCESS}

This section presents a detailed discussion of the decomposition detoxification process. A generic process description provides background, including discussions of process advantages and processing potential. A discussion of process specifics follows, then the section concludes with a technical evaluation of the process.

\section{Generic Process Description}

Currently there are two broad categories of standard technologies for dealing with hazardous wastes. The first class comprises land-based disposal methods including deep-well injection, lagooning, and landfilling. These techniques do not address ultimate destruction of the hazardous constituents of the waste. The second class comprises technologies for destroying the hazardous constituents of the waste by oxidation of the organic components. These latter technologies include chemical oxidation, incineration, and wet air oxidation (WAO), which was discussed previously. Supercritical water oxidation (SCWO) is in competition with the other technologies for destruction and has certain distinct advantages over the standard technologies. These advantages will be discussed later. Land disposal is usually the least expensive option for dealing with hazardous wastes. Processing costs for these destruction technologies are typically an order of magnitude more than those for the disposal methods. There are limitations to all of the standard technologies which limit their applicability and acceptability as treatment options.

The land-based disposal technologies are limited primarily because they do not provide for the ultimate destruction of the wastes. Also, the potential for pollution is a significant problem with these technologies. The pollution ranges from air pollution for lagooning to surface and groundwater pollution for all forms of such disposal. Deep-well injection is not suitable for some wastes because in situ precipitation of solids can cause plugging of the porous rock formation. In addition, injection into potentially unstable formations has, in some instances, led to increased seismic activity. 
The destructive technologies have their own set of limitations. In general, they are applicable to only limited types of wastes, e.g., incineration is not suitable for aqueous wastes unless the waste contains more than about 25 wt\% organic content so that the heating value is high enough to maintain the process. Furthermore, in many instances these techniques result in low destruction removal efficiencies (DREs) that are insufficient to meet regulatory requirements. A specific example of this situation was discussed previously with regard to wet air oxidation (WAO). The potential for environmental pollution is a limitation for these technologies as well. The pollution can occur in any of the process streams either as the result of incomplete destruction, i.e., low DREs, or because of process by-products. Incineration is subject to a particular type of pollution in the form of $\mathrm{NO}_{\mathrm{x}}$ emissions in the off-gas. This pollutant is formed because of the high process temperatures $\left(900\right.$ to $1100^{\circ} \mathrm{C}$ or 1652 to $2010^{\circ} \mathrm{F}$ ) required in order to achieve the high DREs required for successful incineration of hazardous waste. The specific limitations of WAO were discussed previously in more detail.

Supercritical water oxidation (SCWO) of hazardous organic wastes coupled to the geopressured-geothermal resource deserves consideration as the preferred technology for the destruction of certain waste forms. The five major benefits arguing in favor of this technology are as follows:

1. There would be an overall reduction in the volume of organic wastes requiring alternate forms of disposal.

2. There is the potential for very high DREs; values in excess of 99.999\% have been reported for selected compounds (Thomason and Mode11, 1984; Thomason et al., 1988).

3. The effluents produced would contain no hazardous constituents. The organic constituents present would be converted to carbon dioxide and water. Any heteroatom present, such as sulfur, nitrogen and chlorine would be converted to a simple inorganic form. Specifically, chlorine would be converted to chloride salts, sulfur would be converted to sulfate salts and nitrogen 
would be released primarily as diatomic nitrogen (Thomason and Mode11, 1984; Thomason et al., 1988). Mechanistically and kinetically, the oxidation in supercritical water is similar to combustion; however, it takes $\mathrm{place}$ at much lower temperatures than incineration $\left(600^{\circ} \mathrm{C}\right.$ or $1110^{\circ} \mathrm{F}$ compared to around $1800^{\circ} \mathrm{C}$ or $3270^{\circ} \mathrm{F}$ ) so that no higher oxides of nitrogen, $\mathrm{NO}_{x}$, are formed (Rofer and Streit, 1988, 1989; Simoneit et al., 1984).

4. The process provides a readily available arena of disposing of any inorganic products formed during the destruction. Because supercritical water is a poor solvent for inorganics, as discussed previously, the inorganic products would be precipitated from the fluid and would therefore be included as part of the brine slurry recovered from the process and reinjected.

5. The process is applicable to a wide variety of wastes including oils, solids, sludges, organic liquids and aqueous wastes containing organic contamination.

There are other secondary advantages of SCWO which result from the unique properties of SCFs. These are as follows:

1. Destruction occurs as a rapid, complete reaction in a single phase.

2. Because of the short residence times required, the process requires a relatively small system for a given capacity.

3. The process is inherently controllable.

4. The process is readily scalable from very small to very large applications.

5. There is the potential for energy recovery from the process if warranted by the economics. 
Development of the basic process of using supercritical water for the destruction of various wastes, including hazardous waste, has been ongoing for the past 15 years. M. Model1 and coworkers have pioneered in the development of the technology (Thomason and Mode11, 1984; Modell et al., 1983). W. Killilea and collaborators have also been instrumental in process development (Staszak et al., 1987). The technology is currently just entering the commercialization phase of development. Numerous other people have also been active in various aspects of SCWO. C. Rofer and G. Streit (Rofer, 1987; Rofer and Streit, 1989) are investigating the kinetics and mechanisms of oxidation in supercritical water. The specific application of these studies is the treatment of hazardous waste. Additional oxidation kinetics studies have been reported by Helling and Tester (1988). These studies have shown that oxidation in supercritical water proceeds mechanically and kinetically similarly to combustion. However, SCWO occurs at lower temperatures than combustion $\left(600^{\circ} \mathrm{C}\right.$ or $1110^{\circ} \mathrm{F}$ compared to around $1100^{\circ} \mathrm{C}$ or $2010^{\circ} \mathrm{F}$ ) (Rofer and Streit, 1988, 1989; Simoneit et a7., 1984).

A main conclusion reached at a recent DOE workshop on research and development opportunities in SCF technology (EA-Mueller, Inc. and Energetics, Inc. 1989) was that application of SCWO to hazardous waste treatment was one of the most promising areas of development needing to be pursued. An earlier investigation conducted for the U.S. Army Toxic and Hazardous Materials Agency evaluated the applicability of SCFs for contaminant destruction in a variety of matrices including soils and sediments or liquids at U.S. Army installations (Bilello et al., 1982). The study identified four feasible application areas:

1. synthetic resin generation

2. destruction of contaminants in sediments

3. destruction of contaminants in liquids

4. destruction of treatment sludges or surplus explosives.

One of the specific SCF processes considered in the study was SCWO, which was evaluated for destruction of hazardous wastes including contaminated liquids, sludges or explosives. A recent workshop jointly sponsored by the 
U.S. DOE and the U.S. Air Force (Rofer and Wander, 1989) considered applications of SCWO to treatment of so-called high risk wastes including solid propellants, hazardous mixed wastes, i.e., hazardous wastes also containing radioactive constituents, medical/biological wastes and pharmaceutical wastes. There have been other reports in the literature presenting results of studies applying SCWO to biological and pharmaceutical wastes (Thomason et al., 1988; Stone and Webster Engineering Corporation, 1989; Johnston et al., 1988). There have al so been several studies evaluating SCWO for space-related applications, including use in 1 ife-support systems, and comparing this process to other technologies. These examples indicate both the high degree of interest in utilizing SCF technology as well as the wide range of potential applications of SCWO.

Use of SCWO for treatment of aqueous wastes containing organic contamination is the most obvious application as well as the one most frequently explored (Thomason and Mode11, 1984; Staszak et al., 1987; Thomason et a 1, 1988; Stone and Webster Engineering Corporation, 1989). The organic constituents that are suitable candidates for treatment by this process run the gamut from the innocuous residues produced by the food processing industry to more hazardous and refractory compounds such as chlorinated solvents and polychlorinated phenols (PCBs). The SCWO process has a high degree of flexibility, being able to accept wastes with organic concentrations ranging from 2 to $20 \mathrm{wt} \%$; however, the more important parameter is the heating value of the waste. The process is capable of handling wastes with heating values ranging from 350 to $3600 \mathrm{Btu} / \mathrm{lb}(810 \mathrm{~kJ} / \mathrm{kg}$ to $8,400 \mathrm{~kJ} / \mathrm{kg})$. Mixing of wastes to adjust heating value further expands the range of wastes treatable by the process. The process is also compatible with a variety of inorganic constituents present either in the waste or formed from various heteroatoms during destruction of the organic components. Table 3 illustrates the broad variety of constituents amendable to treatment by SCWO. These include organics, inorganics, and biologicals.

For the particular process envisioned, coupling SCWO to the geopressuredgeothermal resource, the types of wastes treated would not be aqueous wastes as such. Rather, organic liquids would be added to the brine to form an 
aqueous stream with the appropriate composition to facilitate treatment, i.e., the heating value of the steam would be adjusted to the acceptable range. A recent report assessing the industrial potential for WAO and SCWO (Stone and Webster Engineering Corporation, 1989) provides insight into the magnitude of wastes available for processing by this technology. According to the report approximately 71 billion gallons (268 million metric tons [Mt] at an approximate density of $8.3 \mathrm{lb} / \mathrm{gal}$ or $1 \mathrm{~g} / \mathrm{cm}^{3}$ ) of hazardous waste as classified by RCRA regulations were generated in 1981. The wastes best suited for treatment by SCWO include spent solvents, both halogenated and nonhalogenated, and ignitable wastes. According to EPA sources cited in the report, approximately three billion gallons (11 Mt) of spent solvents and approximately one billion gallons (3.8 Mt) of ignitable waste were generated nationally in 1981. Another source cited in the report estimated that by 1987 the total hazardous waste generated nationwide had increased to about 75 billion gallons (283 million Mt) per year. Because of the uncertainties associated with the information used to arrive at these values they are not highly accurate, but do serve as order-of magnitude estimates. 
Organic

Chemical

\begin{tabular}{|c|}
\hline 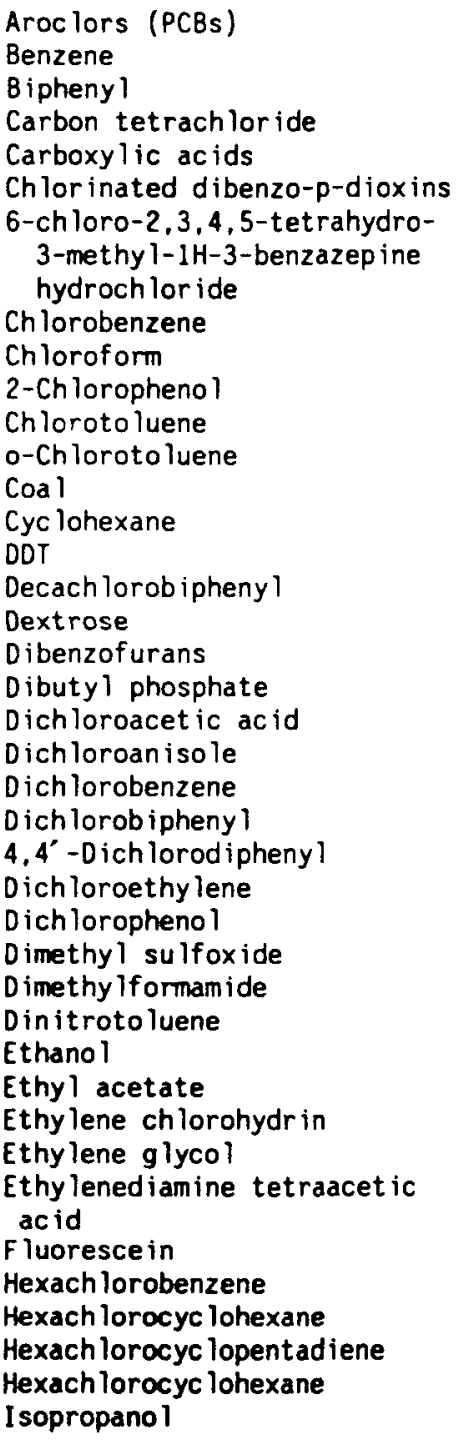 \\
\hline
\end{tabular}

Mercaptans

Methanol

Methyl cellosolve

Methylene chloride

Methyl ethyl ketone (MEK)

Nitrobenzene

Octachlorostyrene

Pentach lorobenzene

Pentachlorobenzonitrile

Pentachloropyridine

Surfactants

Tetrach lorobenzene

Tetrachloroethylene

Tetrapropylene

Tributyl phosphate

Trichlorobenzene

1,1,1-Trich loroethane

1,1,2-Trich loroethane

Trichloroethy lene

Trich loropheno I

Trifluoroacet ic acid

Transformer oil

Urea

$x y$ lenes

\section{Biological Substances}

Bacillus Stearothermophilus (Heat resistant spore)

Carbohydrate

Cellulosics

E. Coli

Endotoxin (pyrogen)

Human waste

Malaria antigen

Paper

Protein

Sulfolobus Acidoca lda

Yeast
Inorganic

Chemical

A lumina

Armonia

Ammonium ch loride

Ammonium sulfate

Boric acid

Calcium carbonate

Calcium chloride

Calcium oxide

Calcium phosphate

Calcium sulfate

Cyanide

Heavy metal oxides

Hydrochloric acid

Iron

Iron oxide

Lithium sulfate

Magnesium oxide

Magnes ium phosphate

Magnesium sulfate

Potassium bicarbonate

Potassium carbonate

Potassium chloride

Potassium sulfate

Silica

Sodium carbonate

Sodium chloride

Sodium hydroxide

Sodium nitrate

Sodium sulfate

Soil

Sulfur, elemental

Titanium dioxide 
A further breakdown of wastes generated in 1985 is presented in the report. These figures are based on a Congressional Budget office document cited in the report. The cited document estimated that in 1985 approximately 73 billion gallons ( 274 million Mt) of wastes are generated. Of these, approximately $7 \%$ ( 5 billion gallons or 19 million Mt) was comprised of waste oils and oily sludges and approximately 6\% (4.5 billion gallons or 17 million Mt) was comprised of organic sludges other than oily sludges. The government document also separates the waste generation by industry. In particular, the petroleum products industry alone is estimated to have generated approximately $12 \%$ of the total hazardous waste. Of this amount $42 \%$ ( 3.7 billion gallons or $14 \mathrm{million} M \mathrm{t}$ ) was waste oil or oily sludge and $25 \%$ ( 2.2 billion gallons or 8 million Mt) was spent solvents, both halogenated and nonhalogenated.

Based on a confidential market evaluation, the report further estimates that, assuming 271 million Mt (72 billion gallons) of hazardous wastes are produced nationwide each year, then approximately 33 million Mt $(8.7$ billion gallons) are waste liquids containing organics and 30 million Mt $(7.9$ billion gallons) are organic sludges. After discounting for recycling and those wastes which would require too much pretreatment, nearly $30 \%$ of the liquid waste and $5 \%$ of the organic sludge could be treated. This amounts to approximately $4 \%$ of the total hazardous wastes produced each year, or 3 billion gallons (11.4 million Mt).

Assuming these wastes have an average density of $8.3 \mathrm{lb} / \mathrm{gal}$ $\left(1 \mathrm{~g} / \mathrm{cm}^{3}\right)$ and an average heating value of $1500 \mathrm{Btu} / \mathrm{gal}(348 \mathrm{~kJ} / \mathrm{L})$, the total energy content is $3.8 \times 10^{13} \mathrm{Btu} / \mathrm{yr}\left(0.038\right.$ quads or $\left.4.0 \times 10^{16} \mathrm{~kJ} / \mathrm{yr}\right)$. Thus there is the potential for recovering significant amounts of energy during the oxidation process.

A recent industry publication (McCoy and Associates, Inc.) presented a compilation of waste generation, by state, for the year 1985. According to these figures 246 million Mt ( 65 billion gallons) of hazardous waste were generated nationally for that year. It should be noted that these figures are somewhat lower than those presented above; this indicates the magnitude of uncertainties inherent in the estimates. For 1985, Texas was the state 
generating the most hazardous waste at $14.3 \%$ of the total $(35.2$ million Mt or 93 billion gallons). In addition, Louisiana ranked number seven in terms of hazardous waste generation at approximately $5 \%$ of the total (12.4 million Mt or 3.3 billion gallons). From these figures it is evident that there is the potential for large volumes of suitable hazardous wastes to be available within reasonable distances of the resources selected. Therefore, transportation costs should not impact process economics too significantly.

To briefly summarize the previous discussion of the properties of supercritical water, above its critical point $\left(374.1^{\circ} \mathrm{C}\right.$ or $705.4^{\circ} \mathrm{F}$ and $218.3 \mathrm{~atm} ; 3208 \mathrm{psia}$ or $22.12 \mathrm{MPa}$ ) water exhibits properties which make it eminently suitable as a medium for destruction of most organic compounds. The high dielectric constant of liquid water $(80)$, ascribable to the hydrogen bonding present in the liquid, decreases to approximately 2.5 with the concomitant weakening and disappearance of hydrogen bonding. In addition, there is a corresponding decrease in fluid density from $1 \mathrm{~g} / \mathrm{cm}^{3}\left(62.4 \mathrm{lb} / \mathrm{ft}^{3}\right)$ to around $0.3 \mathrm{~g} / \mathrm{cm}^{3}\left(18 \mathrm{lb} / \mathrm{ft}^{3}\right)$. The net result of these two effects is a pronounced change in the solvent properties of water. As the critical point is approached there is a sharp decrease in solubility of inorganic compounds with a corresponding sharp increase in solubility of organic compounds and nonpolar gases; supercritical water is a poor solvent for inorganics and a good solvent for organics.

In addition to its solvent properties, supercritical water also exhibits the surface tension, viscosity and diffusivity behavior typical of such a fluid. This makes possible rapid mixing of constituents in a single phase without use of mechanical stirring or agitation. Furthermore, reaction kinetics are not diffusion limited. Also, as noted before, oxidation in supercritical water is similar to combustion, but occurs at a lower temperature. Thus, no higher oxides of nitrogen are formed. The product formed from any nitrogen present in the combined form is nitrogen gas.

As noted, the proposed SCWO process has potential applicability to a wide variety of wastes containing organic constituents. The process itself would be particularly appropriate for aqueous media, such as wastewater or 
ground-water contaminated with organics. This type of application would be appropriate for an on-site treatment facility. Where the SCWO process is being coupled to the geopressured-geothermal resource such aqueous wastes would not be appropriate as feedstocks. In the first place, transportation costs associated with shipping the volumes of water involved would mitigate against the economics of processing this type of waste. Furthermore, the waste would be further diluted by addition to the brine stream from the resource, making the heating value of the combined stream too low to process without addition of extra fuel. Again, this would also adversely impact treatment economics.

Additionaliy, the process could also be applied to organic liquids, slurries, sludges or solids. The latter could be in the form of solid organics or solids contaminated with organics. Solids would have to be slurried with brine or water to facilitate being introduced into the process steam. Liquids and sludges would be the wastes chosen for the initial process demonstration phase because of the ease of handling. As with aqueous media, treatment economics would most generally preclude processing solids, such as contaminated soils, in the type of off-site facility proposed.

In the proposed SCWO application, processing would occur at or above supercritical conditions for water. These conditions are not directly available from the geopressured-geothermal resource. Typical wellhead conditions are about $150^{\circ} \mathrm{C}\left(302^{\circ} \mathrm{F}\right)$ and $204 \mathrm{~atm}(3000 \mathrm{psia}$ or $20.7 \mathrm{MPa})$, corresponding to slightly below critical pressure and well below critical temperature. The methane or other combustible gas present in the brine would be oxidized along with waste, with the heat released used to raise the fluid temperature above the critical point. Waste and compressed air would be injected into the supercritical water, where the organics would be rapidly oxidized. Residence times for complete destruction are typically on the order of 1 minute or less.

With $2 \%$ or more of combustible waste, the reaction should become selfsustaining. Because of the high rate of the combustion process, operation approaches adiabatic conditions, with heat losses being small. For example, if compressed air is used as the oxidizer and the feed contains about 5 wt\% of 
organics with an inlet temperature of $400^{\circ} \mathrm{C}\left(752^{\circ} \mathrm{F}\right)$ at about 250 atm ( $3670 \mathrm{psia}$ or $25.3 \mathrm{MPa}$ ), fluid outlet temperatures from the reactor on the order of 500 to $600^{\circ} \mathrm{C}\left(932\right.$ to $\left.1110^{\circ} \mathrm{F}\right)$ should be attainable. Temperature at reactor outlet will depend upon specific inlet conditions and concentration of organics in the feed. At an outlet temperature of around $600^{\circ} \mathrm{C}\left(1110^{\circ} \mathrm{F}\right)$ the process will become autogenic.

Under the operating conditions above, reaction of most organics should be essentially complete, with the primary reaction products being carbon dioxide and water. Although this oxidation is similar to combustion, formation of nitrogen oxides should be negligible because of the much lower temperatures, in contrast to those typical of incineration $\left(1800^{\circ} \mathrm{C}\right.$ or $\left.3270^{\circ} \mathrm{F}\right)$. In addition, any inorganics present would precipitate under these conditions and could be separated out by use of a hydrocyclone.

Heat would be recovered from the fluid leaving the reactor outlet to preheat the makeup streams. Blowdown will be taken from the bottom of the reactor to prevent solids buildup in the system. After letdown from reactor conditions, the brine from the blowdown will be reinjected into the reservoir. At reactor outlet conditions, after removing precipitated solids, the fluid would be a mixture of relatively pure superheated steam, carbon dioxide, and nitrogen. This fluid will be passed through a turbine to provide energy for operating the system air compressor and pumps.

Process specifics will depend on actual reservoir conditions and waste feed composition. These details would be finalized during detailed process design to optimize the over all process and economics.

\section{Discussion of Process Specifics}

Because of the proprietary nature of the commercially available technology, vendors would not provide definitive process information. However, the process proposed is conceptually modeled after those of vendors (Thomason and Mode11, 1984). 
Because the purpose of the study has been to evaluate the overall technical and economic feasibility of the SCWO process coupled to the resource, no attempt has been made to improve the economics by adding additional processes.

The design is based upon a total system throughput of 100,000 gpd $(455,000 \mathrm{~L} / \mathrm{d})$. This size is at the upper limit of current commercial design and was chosen to provide the highest waste throughput practical. As such, economics of scale of processing will be possible, reducing processing costs per gallon of waste. The process is designed as a once-through system.

The waste is an organic liquid with a heating value of $18,000 \mathrm{Btu} / 1 \mathrm{~b}$ $(41,900 \mathrm{~kJ} / \mathrm{kg})$. The total waste throughput is $10,000 \mathrm{gpd}(3055 \mathrm{lb} / \mathrm{h}$ or $1386 \mathrm{~kg} / \mathrm{h}$ ). For design purposes the brine is assumed to be available at the wellhead under flowing conditions of $300^{\circ} \mathrm{F}\left(149^{\circ} \mathrm{C}\right)$ and 3000 psia (204 atm or $20.7 \mathrm{MPa}$ ). The brine also contains dissolved gas at $35 \mathrm{scf} / \mathrm{bbl}\left(0.83 \mathrm{scf} / \mathrm{gal}\right.$ or $\left.0.0447 \mathrm{Nm}^{3} / \mathrm{L}\right)$, of which $90 \%$ is methane. The methane provides the brine with approximately $600 \mathrm{Btu} / \mathrm{gal}(139 \mathrm{~kJ} / \mathrm{L})$ of energy that can be recovered in the process. The brine is assumed to contain $127,000 \mathrm{mg} / \mathrm{L}(1.06 \mathrm{lb} / \mathrm{gal})$ total dissolved solid (TDS). The waste and brine are fed to the reactor to provide a combined flow containing approximately $10 \mathrm{wt} \%$ organic content. Thus, at the design waste-flow rate, a total brine throughput of $90,000 \mathrm{gpd}(409,000 \mathrm{~L} / \mathrm{d})(30,000 \mathrm{lb} / \mathrm{h}$ or $13610 \mathrm{~kg} / \mathrm{h})$ is required.

In the design case, air is used as the oxidant and is added at $10 \%$ in excess of stoichiometric requirements. At design conditions this requires an air flow rate of $46,200 \mathrm{lb} / \mathrm{h}(20,960 \mathrm{~kg} / \mathrm{h})$.

The waste, brine, and air are pressurized and heated to reactor conditions which are about $594^{\circ} \mathrm{C}\left(1100^{\circ} \mathrm{F}\right)$ and $251.8 \mathrm{~atm}(3700$ psia or $25.51 \mathrm{MPa})$. Upon mixing a homogeneous phase of air, organics, and supercritical water, containing precipitated salts, is formed. Under these conditions the organics are oxidized in a rapid but controlled exothermic reaction. At these conditions DRES $>99.999 \%$ should be attainable at residence 
times less than 1 minute. The relatively short residence time means that the reactor operates essentially adiabatically. Thus, the heat released is adequate to raise the fluid to temperatures sufficient to ensure rapid oxidation of even refractory organics.

To control solids buildup in the reactor, a portion of the fluid is bled off at the bottom to remove excess solids. This stream passes through a heat exchanger to recover energy for heating the feed streams. From the heat exchanger, the stream is flashed and quenched to ambient. Quench water is added to produce about a 20 wt\% brine which is reinjected for disposal.

The major products of the oxidation are carbon dioxide and water. Nitrogen heteroatoms present in the organic produce primarily nitrogen. Other heteroatoms will produce smaller quantities of inorganic salts such as chlorides and sulfates. These additional inorganics will make a negligible contribution to the total solids present from the brine. The fluid exiting the top of the reactor will consist primarily of water, carbon dioxide, and nitrogen. It emerges from the reactor at very high temperature and pressure and is a viable source for recovery of energy.

Downstream of the reactor, the product fluid stream passes through a heat exchanger where thermal energy is recovered to heat the feed streams entering the reactor. Even after heat exchange the product stream is at a temperature and pressure suitable for driving a gas turbine. With a feed stream of sufficiently high energy content the energy extracted by the turbine can produce excess energy over that required to compress or pump the various process streams. For the design case, the excess energy available is about $2800 \mathrm{hp}$ (2.1 MWe).

Turbine exhaust is condensed and used as a source of quench water for the solids removed from the reactor.

Figure 5 is a schematic process flow diagram (PFD) for the process at design conditions. The process can operate over a range of organic concentrations at the reactor inlet from 2 to $20 \mathrm{wt} \%$ allowing operation over a 
range of 350 to $3600 \mathrm{Btu} / \mathrm{lb}(810 \mathrm{~kJ} / \mathrm{kg}$ to $8400 \mathrm{~kJ} / \mathrm{kg})$ energy content of the combined makeup stream. Table 4 presents a summary of the process parameters used to develop the design case.

Table 4. Process parameters for SCWO.

Reactor Inlet Temperature: $594^{\circ} \mathrm{C}\left(1100^{\circ} \mathrm{F}\right)$

Reactor Pressure: 251.8 atm (3700 psia or $25.51 \mathrm{MPa}$ )

Organic Concentration: $10 \mathrm{wt} \%$ (Range: 2 to $20 \mathrm{wt} \%$ )

Feed Heating Value: $1800 \mathrm{Btu} / \mathrm{lb}(4190 \mathrm{~kJ} / \mathrm{kg})$

(Range: 350 to $3600 \mathrm{Btu} / \mathrm{lb}$ or

$810 \mathrm{~kJ} / \mathrm{kg}$ to $8400 \mathrm{~kJ} / \mathrm{kg}$ )

Reactor Residence Time: $\sim 1 \mathrm{~min}$

Destruction Removal Efficiency (DRE): $\geq 99.999 \%$

Oxidant: Air or 0xygen $-10 \%$ excess

Flow Rate: 100,000 gpd $(455,000 \mathrm{~L} / \mathrm{d})$ 


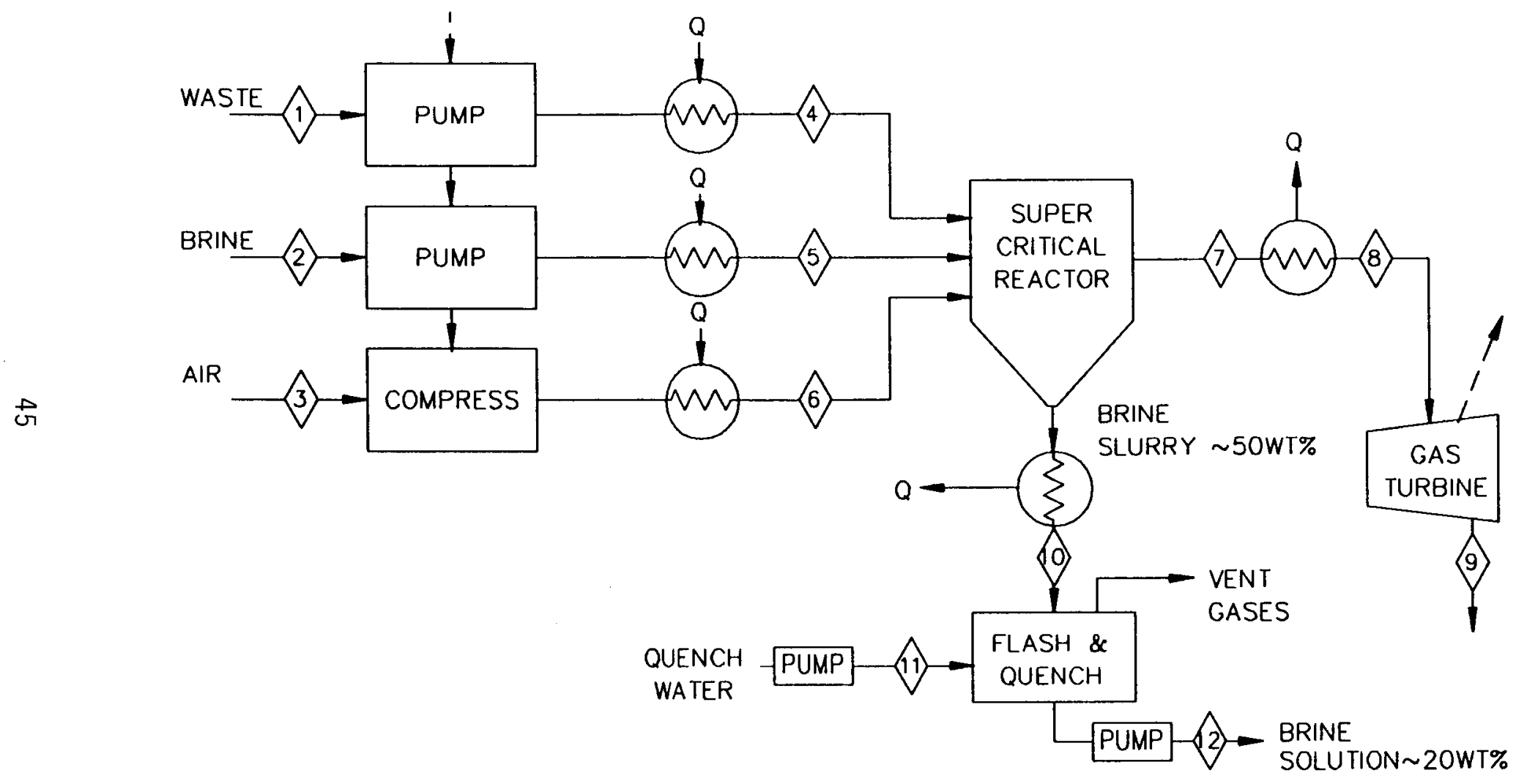

\begin{tabular}{|c|c|c|c|c|c|c|c|c|c|c|c|c|}
\hline STREAM NUMBER & 1 & 2 & 3 & 4 & 5 & 6 & 7 & 8 & 9 & 10 & 11 & 12 \\
\hline PRESSURE (PSIA) & 14.7 & 3000 & 14.7 & 3700 & 3700 & 3700 & 3700 & 3700 & 40 & 3600 & 3600 & 10000 \\
\hline TEMPERATURE $\left({ }^{\circ} \mathrm{F}\right)$ & 70 & 300 & 70 & 1100 & 1100 & 1100 & 2785 & 1200 & 270 & 300 & 70 & 145 \\
\hline FLOW (LB/HR) & 3055 & 30100 & 46200 & 3055 & 30100 & 46200 & 75215 & 75215 & 75215 & 4140 & 14725 & 18865 \\
\hline
\end{tabular}

Figure 5. Conceptual process flow diagram: Decomposition/Detoxification process for $1000,000 \mathrm{GPD}(455,000) \mathrm{L} / \mathrm{d})$. 
. 


\section{Technical Evaluation}

The significant processing potential represented by hazardous wastes suitable as feedstocks for the SCWO process has been clearly established in the previous discussion of the generic process. Furthermore, it has also been shown that abundant volumes of feedstocks should also be readily available within reasonable proximity of the resource. However, the technical viability of the SCWO process has not yet been addressed nor the feasibility of coupling the process to the geopressured-geothermal resource. These topics will be discussed below.

As stated previously, the proprietary nature of the SCWO technology currently available precluded obtaining definitive process information from vendors. Thus, the schematic process flow diagram, figure 5 , is conceptual in nature, lacking the higher level of specifics required for detailed process design and optimization. In addition, the process simulation was idealized, not taking into account in detail all of the process losses such as heat loss from the reactor. Development of a detailed process design will require, in addition to specifics on actual reservoir conditions and waste feed composition, close collaboration with vendors, which was beyond the scope of this study.

Conceptually, the SCWO process coupled to the geopressured-geothermal resource provides an attractive means of destroying hazardous organic waste to produce environmentally benign effluents while utilizing the energy of the resource to offset the energy requirements of the destruction process. In point of fact, as discussed previously, energy in excess of process input requirements can be produced. If this energy, equivalent to about 2.0 MWe (2680 hp) is recovered as electricity and sold, additional revenues would be generated to offset processing costs. This would reduce disposal costs, making the process more attractive economically as an alternative disposal technology. 
In an energy balance for a facility using air as the oxidizing agent (Table 5), by far the largest energy consumption in the process is the requirement for the air compressor. The compressor accounts for $7100 \mathrm{hp}$ (5.3 MWe), corresponding to $96 \%$ of the work input. Significant savings in compressor energy requirements can be achieved by using an oxygen enriched oxidizing medium, as shown in Table 6 for 99\% oxygen as the oxidizer. Under these conditions compressor requirements drop drastically to only $1500 \mathrm{hp}$ (1.1 MWe). In this scenario, the excess output from the turbine increases to almost $4980 \mathrm{hp}$ ( $3.7 \mathrm{MWe})$, providing additional electrical power.

Since air is composed of over $78 \%$ nitrogen by volume, an additional advantage of using an oxygen enriched oxidizing medium will be a reduction in the size required for the reactor, which is one of the major capital costs for the facility. However, the reduction in cost of the reactor will be more than offset by the cost of an enrichment facility or, as an alternative, the rental of a facility to store and handle liquid oxygen.

The scientific feasibility of the SCWO process itself has been well established by numerous bench-scale and small pilot-scale studies, with the pilot-scale unit having a nominal capacity of $500 \mathrm{gpd}(2300 \mathrm{~L} / \mathrm{d}$ ) (Thomason and Mode11, 1984; Rofer, 1987; Rofer and Streit, 1988, 1989; Staszak et a 1., 1987; Thomason et al., 1988; Stone and Webster Engineering Corporation, 1989; Mode 11 et a1., 1983; Helling and Tester, 1988; Rofer and Wander, 1989; Johnston et al., 1988). The wide variety of constituents subjected to treatment in these and other related studies has already been indicated in Table 3 . These studies have shown that the DRE is a direct function of reactor temperature, as would be expected (Thomason and Mode11, 1984). As a corollary to higher DREs, higher temperatures reduce the reactor residence times required to obtain complete destruction of the organic components, even the more refractory ones. The process operating parameters of temperature, pressure, and reactor residence time, as 1isted in Table 4, have been selected consistent with the body of experimental results to achieve the DREs 
Table 5. Energy balance for a $100,000 \mathrm{GPD}(455,000 \mathrm{~L} / \mathrm{d})$ processing plant utilizing air as the oxidizing medium.

\begin{tabular}{|c|c|}
\hline \multicolumn{2}{|c|}{ ENERGY INPUTS } \\
\hline$W(h p)$ & $\underline{0}(\mathrm{MBtu} / \mathrm{hr})$ \\
\hline 17.6 & 1.95 \\
\hline 7100.0 & 9.15 \\
\hline 33.7 & 39.05 \\
\hline 72.5 & -- \\
\hline 177.5 & $\ldots$ \\
\hline 7401.3 & 50.15 \\
\hline
\end{tabular}

ENERGY OUTPUTS

$\underline{W(h p)} \quad \underline{0(M B t u / h r)}$

Hot exhaust (turbine, heat

exchange)

Slurry (heat exchange)

TOTAL
10,130

$\frac{--}{10,130}$
49.75

5.60

55.35 
Table 6. Energy balance for a 100,000 GPD $(455,000 \mathrm{~L} / \mathrm{d})$ processing plant utilizing $99 \%$ oxygen as the oxidizing medium.

\section{ENERGY INPUTS}

W (hp)

17.6

Waste (pump, heat exchange)

oxygen (compressor, heat exchange)

Brine (pump, heat exchange)

Quench water (pump)

Brine return (pump)

TOTAL

1801.3

$\begin{array}{r}17.6 \\ 1500.0 \\ 33.7 \\ 72.5 \\ 177.5 \\ \hline 1801.3\end{array}$

ENERGY OUTPUTS

W (hp)

$\underline{Q}(\mathrm{MBtu} / \mathrm{hr})$

Hot exhaust (turbine, heat exchange)

Slurry (heat exchange) TOTAL
$\underline{Q}(\mathrm{MBtu} / \mathrm{hr})$

$$
1.95
$$

2.06

39.05

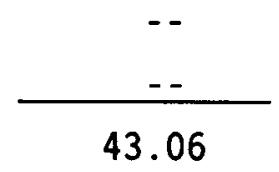


mandated by regulatory requirements while minimizing capital equipment costs related to high temperature and pressure operation. The nominal reactor residence time of one minute provides a reasonable safety factor to assure complete destruction of all organics present without requiring unacceptably large reactor volumes.

For waste streams containing only very low levels of inorganic constituents and organics with no heteroatoms to form inorganic acids, e.g., chloride, sulfur, or phosphorous, design requirements for the reactor are straight forward with the only criterion being to provide sufficient residence time at conditions to assure complete oxidation. However, when inorganic compounds are present, either in the feed or as products of the destruction process, their insolubility under supercritical conditions, as discussed previously, causes their precipitation and can lead to deposition and plugging in the reactor. Under these conditions, reactor design requirements are much more stringent. These types of problems have been observed experimentaliy, leading the vendors to develop proprietary reactor designs in which the precipitated solids are separated and removed from the remainder of the reactor effluent. These reactor designs have been tested at the $500 \mathrm{gpd}$ $(2300 \mathrm{~L} / \mathrm{d})$ pilot scale with some success. However, additional design modifications have been required that have been tested at the bench scale but will require testing at further scale up beyond $500 \mathrm{gpd}(2300 \mathrm{~L} / \mathrm{d})$ for successful demonstration (Stone and Webster Engineering Corporation, 1989).

The issue of the inorganic solids content of the fluid in the reactor is exacerbated by the dissolved solids loading in the resource brine. The SCWO process has not previously been demonstrated under similar conditions of such high solids loading. However, the process in theory can accept such loadings, and the vendors have expressed optimism that with modification, as required, the process can be successfully coupled to the geopressuregeothermal resource. To resolve this issue bench scale testing and engineering design will be required. A further issue involves the turbine shown in the PFD, Figure 5 , used for direct energy recovery from the process. A turbine suitable for this service is not currently available, al though there have been expressions of interest from various vendors in pursuing development 
of equipment for such an application (Stone and Webster Engineering Corporation, 1989). The two potential problem areas are the relatively high impurity levels anticipated for the fluid influent to the turbine and the high temperature and pressure conditions of the fluid, which are beyond those experienced in conventional turbine operation. Section 9 of the Stone and Webster report provides a detailed discussion of this issue (Stone and Webster Engineering Corporation, 1989).

Direct energy recovery has been used for this conceptual process because it will be the most energy efficient as well as being potentially the most economical from a capital equipment standpoint. The final viability of this particular option would be determined during the later detailed design phase if proceeding with a demonstration of this application of SCWO coupled with the geopressured-geothermal resource was pursued.

There is an alternate option for recovering energy from the process effluent. In this option, heat would be exchanged from the SCWO reactor effluent to a secondary fluid that would be used to power a turbine. The secondary fluid could be water operating in a closed loop. This option would require higher capital equipment costs and produce lower energy recovery efficiencies. For these reasons, the use of direct energy recovery was considered as preferable for the economic analysis that follows.

In summary, the scientific viability of the proposed process has been established. There are issues associated with the engineering feasibility, but there are options that will allow these issues to be resolved. Thus, overall the process of coupling SCWO to the geopressure-geothermal resource has been evaluated as being technically feasible. 


\section{ECONOMIC EVALUATION}

This section discusses the economic methodology and assumptions in the geopressured-geothermal SCWO economic model. Developed in LOTUS-123, this menu-driven model can calculate the breakeven price or payback period in the destruction of hazardous organic wastes using a geopressured-geothermal resource.

\section{Economic Methodology}

An economic methodology is an established method used to evaluate all investments on an equal basis. This study uses the present value (PV) methodology to evaluate the breakeven cost for disposing of hazardous organic wastes and producing electricity from excess heat using a geopressuredgeothermal resource. Also referred to as discounted-cash-flow-analys is (DCFA), PV analysis is the preferred method of analysis when evaluating projects with differing cashflows over different time periods. The PV analysis is a simple process of equating all cash flows to an assigned base year. Future dollars are discounted by using a single-payment, present-worth (PW) factor, also referred to as the discount factor. This simple but important factor is calculated by

PW Factor $=1 /(1+i)^{n}$

where

$$
\begin{aligned}
& i=\text { annual discount rate } \\
& n=\text { number of annual discounting periods. }
\end{aligned}
$$

The PV is obtained by multiplying the PW factor by the expected future value. For example, if we expect to receive $\$ 100.00$ two years from now, we would be indifferent to receiving $\$ 82.64$ today, assuming our discount rate was $10 \%$. This is calculated from

$$
\$ 100.00 * 1 /(1+0.1)^{2}=\$ 82.64 .
$$


The reciprocal concept of $P V$ is future value (FV). This concept allows us to estimate a future value from a known or estimated present value. The present cost is compounded to a future value by a single-payment, compound-amount factor, also referred to as the future worth (FW) factor. This second important factor is calculated by

$$
\text { FW Factor }=(1+i)^{n}
$$

where

$i=$ annual discount rate

$n=$ number of annual discounting periods.

The FV is obtained by multiplying the FW factor by the current value. For example, if we expect to receive $\$ 100.00$ today, we would be indifferent to receiving $\$ 121.00$ two years from now, assuming our discount rate was $10 \%$. This is calculated from

$$
\$ 100.00 \star(1+0.1)^{2}=\$ 121.00 .
$$

It is important to understand that PV and FV are identical concepts, depending only on the point of view. For example, using the example above, $\$ 100$, in 1990 dollars are equivalent in value to $\$ 121$ in 1992 dollars (the FV concept); conversely, $\$ 121$ in 1990 dollars are equivalent to $\$ 100$ in 1988 dollars (the PV concept). It is entirely dependent on the base year identified and the relationship of the cash flow to that year.

\section{Determining The Discount Rate}

The discount rate is an arithmetic factor that must be determined by the investor or equity holder. At a minimum, the discount rate accounts for the time value of money and the perceived risk of investment, the two major concerns of the investor. Initially, the investor identifies competing money markets of similar risk to establish a rate. Currently, any investor can invest in almost risk free treasury bonds and bills and receive 7.0 to $8.0 \%$ annually (Wall Street Journal, 1990). At a minimum, any alternative investment with similar characteristics should return this minimum rate or the 
investor would invest in bonds or bills for a higher rate of return on investment. If the investor is looking for a riskier, higher rate of return, commercial bonds and bills are available that return 10 to $14 \%$ and even higher. In effect, the higher the risk, the higher the rate has to be to attract investors. Discount rates as high as $40 \%$ can be found with extremely risky investments such as defaulting companies and startup companies with unproven technology.

The discount rate is also established by the experience of the investor. In many instances, the investor has successfully invested in high risk ventures and has established acceptable risks and rewards by personal experience. Through this experience, an internally generated discount rate has been established that allows the investor to take risks and avoid long-term financial failure. Using too high a discount rate may preclude the investor from investment opportunities and the resulting financial rewards; too low a discount rate may contribute to investment loss and ultimate investment failure.

\section{Breakeven Price}

As previously stated, the PV methodology is used to evaluate the cash flows of each investment opportunity and calculate a breakeven price to treat hazardous organic wastes using a geopressured-geothermal resource. The breakeven price is often referred to as the cost-to-produce. Determining the breakeven price requires accounting for a 11 costs and revenues and determining the per unit product price so that the present value of all positive cash flows (revenues) equals the present value of all negative cash flows (costs) over the life of the project. The calculated value is a benchmark to the investor, a benchmark to proceed or not to proceed with the project. When the breakeven price is greater than the current market price, the project would be uneconomical because the price received per unit of production in the market would not cover the full cost of production. Conversely, if the breakeven price is less than the current market price, the investment opportunity would be considered economical because the market price will cover the full cost of production. 


\section{Discounted Payback Analysis}

Payback analysis is a simple analysis method used as a quick and simple investment guide. A discounted payback analysis uses the PV concept of discounted cash flows and calculates the time required for discounted value of revenues to equal the value of investment. An important consideration in this analysis is using a per unit product price for each product that is currently traded in the marketplace or is expected to be in the marketplace in the future. The drawback of this analysis is that the project is not evaluated over the entire project life for profitability or the timing of cashflows after the payback period.

Investors and lending institutions typically use this method of analysis to assess the time to recover their investment. The shorter the payback period, the less risky the investment because market conditions are less subject to change in a shorter period than over a longer period.

\section{Net Present Value}

Net present value (NPV) is another method of analysis that determines the net value added of a project. As the name of the analysis implies, all cost and revenue streams are accounted for over the 1 ife of the project and the initial investment is subtracted from the present value of revenues less costs. As in payback analysis, an important consideration is using a per unit product price that is expected throughout the 1 ife of the project. The drawback of this analysis is that the timing of cashflows is not evaluated respective of a developer's goals.

Again, investors and lending institutions typically use this method of analysis to assess the overall profitability of a project, selecting the project with the overall higher NPV. 


\section{ECONOMIC ASSUMPTIONS}

Investment in the energy industry has proven to be very risky over the last 15 years because of the unstable energy markets and unpredictable price swings. A hazardous waste disposal facility that depends on a geopressured-geothermal resource may prove to be more risky than other disposal projects because of unforeseen production problems in both fields and the higher than normal cost of capital per unit of capacity. This is in addition to the low probability in locating, developing, and operating a waste disposal facility, especially with the growing public concern and negative perception these facilities have generated.

Development of an economic model to evaluate all costs of these facilities should include variables so that the investor can evaluate all variables and assess their price sensitivity. These variables are discussed in more detail under the following headings: "Financial and Economic Variables," "Preoperation Variables," "Operation Variables," and "Postoperation variables."

\section{Financial and Economic Variables}

The financial and economic variables are generic to the investment process. The following variables are discussed as the most likely situation faced by a geopressured-geothermal hazardous waste management industry.

Business Type The analysis assumes the developer will be a large, successful, and integrated company with technical and financial experience in oil, gas, or geothermal development. The technical experience for hazardous waste handling and disposal may be bought as a service or integrated through project participation. Use of a large developer or large group of developers allows us to make the following assumptions. 
Debt Ratio and Interest Rate Two sources of funds are available to a developer: owner's equity and borrowed capital. Currently, the oil and gas industry is capital short and experiencing a reduction of assets. Current debt to equity ratio is $60 / 40$ (U.S. Department of CommerceInternational Trade Commission, 1989). Assuming these current market conditions, we can conservatively estimate a geopressured-geothermal/SCWO developer will be able to borrow $40 \%$ of the capital requirement at the current prime lending rate of $10 \%$ (U.S. Department of CommerceInternational Trade Commission, 1989). This allows for $40 \%$ of the well field development and capital building, equipment, and improvements to be financed by debt. The costs of environmental assessment, public review and comment, site procurement, well study, and well engineering are funded $100 \%$ by owner's equity because these would have to be incurred to prove project viability. Construction interest is funded $100 \%$ by debt.

Operating Losses Assuming a large developer will have other income streams, operating losses from the geopressured-geothermal/SCW0 development will be considered a loss against other income. This allows us to reduce the annual loss against the development by the effective tax rate.

Liquidity Assuming a large developer will have positive cash flows from other operations, all near-term cash requirements are covered.

Base Year The analysis assumes the project will begin construction in 1994, however, initial investment with the site selection/ environmental assessment work begins in 1991, thus 1991 was selected as the base year. Because most of the costs were identified in 1990 dollar values, these values are inflated to the year that the cost is expected to be incurred. Costs that are estimated in pre-1990 dollars are inflated to 1990 using only the inflation rate. Estimated costs and revenues for the years following 1994 are inflated and escalated to the appropriate year. 
Operating Life The operating life of the project is entirely dependent on the projected resource 1 ife; a ten year resource and operating life is assumed. An operating life greater than ten years was not considered because a resource life greater than ten years would be, at this time, considered very optimistic. Additionally, the high discount rate preferred in this analysis minimizes the economic gain of most projects beyond the ten year life.

Debt Life Because of the high risk and unknown variables of this project, three year debt life was assumed. Matching the debt life to five years or longer was not considered because conservative investors typically require a shorter debt 1 ife for high-risk investments.

Construction Life There would be a four year preconstruction life, starting one-half year before the base year and overlapping with the construction period. This first year of the preconstruction period is referred to as year zero; however, the majority of the capital expenditures would occur during the fourth year. Production would begin at the start of the fifth year and end in the fourteenth year. There would be a 1-1/2 year construction 1 ife, starting and overlapping onehalf year with the preconstruction period. The production period would begin at the end of the construction period.

Depreciation and Depreciation Life All preoperational costs will be depreciated by a straight line method over a seven year period according to the 1988 tax law (U.S. Internal Rescue Service, 1988). Straight-line depreciation is more conservative than accelerated depreciation schedules because the investment is depreciated more slowly over the same number of years. The predevelopment costs of well study, engineering, and testing are expensed in the first year of operation, year five. There is no salvage value to any equipment because of the hazardous characteristics of the waste processed. 
Discount Rate Three after-tax income rates of 15, 21 and $26 \%$ are assumed. Three discount rates are selected because of the tremendous variance in the anticipated development schedule and cost of development and operation. A pre-tax discount rate of 20 to $30 \%$ is typical for 011 and gas developments (Borchert and Aumus, 1989). To enhance the conservative approach of this analysis, all discount rates are after-tax. A $26 \%$ after-tax discount rate is used for those investors that consider the development a high risk because of the unproven technology. This high risk factor will naturally reduce the economic viability of any project with an anticipated 4 year lead-time before production can proceed. Discount rates of 21 and $15 \%$ were also investigated to incorporate the situation as more knowledge is gained and uncertainty is reduced.

The conservative approach to the economic analysis is enhanced by using the after-tax discount rate and discounting the cash flows to the beginning of the year. Discounting each year's cash flow to the beginning of the year reduces the actual cash flows by 1 year. The after-tax discounting adds to the conservative analysis by paying all taxes before calculating an expected rate of return.

Inflation and Escalation Rates Inflation is the general rise in the cost of goods and services within an economy. Using 1982 to 1984 as the base year, the Consumer Price Index (CPI) has inflated from 30.9 (January 1964) to 129.9 (June 1990) for an average of $5.0 \%$ per year (U.S. Department of Commerce, Bureau of Economic Analysis, 1989). The CPI is commonly quoted because it represents a broad range of goods and services within our society. Including the 25 years before January 1964, the average CPI was $4.0 \%$ per year. Escalation is the additional price rise above the rate of inflation, usually identified for a certain product or service sector such as fuels or medical services.

The analysis conservatively assumes a $5.0 \%$ inflation rate for all preoperationa1, operational, and postoperational costs and expenses. Additionally, the analysis assumed that all development, construction, or 
operation costs and expenses will not inflate faster than this assumed inflation rate because of the wide array of cost factors and inputs.

Electricity and waste disposal fees are assumed to escalate 0.5 and $2.0 \%$, respectively, because this product and service are anticipated to be in short supply and high demand as a result of international energy and environmental pressures.

Depletion Allowance There will be no depletion allowance. Because the analysis assumes a large developer, the new tax law will not allow percentage depletion for any large producer of oil or gas.

\section{Preoperational Variables}

Preoperational variables are those costs, expenses, and considerations incurred before the operation of the project. All costs are estimated in 1990 dollars and inflated to 1991, 1992, 1993, or 1994 dollar values. These costs are discussed under the headings of development, equipment, working capital, and capitalized interest.

Predevelopment Costs Predevelopment costs are those costs incurred before well field development and installation of buildings and equipment. The majority of these costs are estimated by experience in the development of regional hazardous waste disposal sites throughout the nation's regional compacts and states. A single source of this information is not available at this time and if available would provide data of extreme variances because of the differing public resistance to the siting of these facilities. It is assumed that these are best guess estimates at this time, accepting the fact that identifying and estimating a reasonable cost is better than ignoring this necessary process altogether.

Disposal Site Selection For this analysis, $\$ 100,000$ to select one out of the many preliminary sites technically available for geopressuredgeothermal/SCWO development is assumed. Initial market studies would also be performed to optimize transportation factors. 
Initial Public Comment For this analysis, $\$ 150,000$ to ascertain which site shows the greatest probability for acceptance by local residents is assumed. These data are added to the initial site selection data to determine the best site.

Site Assessment and Characterization For this analysis, $\$ 600,000$ to determine characteristics such as water table, fault lines, or flood plains that would be potentially damaging and would reduce the likelihood of successfully completing the project is assumed.

Draft and Final EIS and Public Comment For this analysis, $\$ 1,000,000$ and 600,000 to draft and finalize documents that may be required to obtain final licensing and permitting from state and federal officials is assumed.

Permitting For this analysis, an additional $\$ 250,000$ to obtain the required permits for construction and operation is assumed.

Site Procurement The analysis assumes a procurement cost for the geopressured-geothermal well field of $\$ 135,000$. Development rights are obtained by a royalty fee equal to $1 \%$ of gross revenues generated.

Well Study The analysis assumes a $\$ 35,000$ geopressured-geothermal field well study to interpret the lithology and production history. This cost is in addition to the initial site characterization study.

We11 Engineering The analysis assumes a $\$ 25,000$ well engineering cost. Included are well logs and analyses necessary to establish the production well's condition and recommend development procedures.

Production Well Development Rework The analys is includes $\$ 1,650,000$ to rework the geopressured-geothermal well field.

Well Testing The analysis assumes a well test cost of $\$ 110,000$ for the geopressured-geothermal well field. We11 testing includes short-term 
flow testing to establish well productivity, to enable accurate brine chemical analyses and to determine reservoir parameters. This information will be required as input to final equipment design, sizing, process controls and operations.

Injection Disposal Well Development Because all brine is eventually injected or disposed of into the aquifer, only one cost is assumed.

Disposal Well Development For this analysis, $\$ 140,000$ to drill a disposal well in the geopressured-geothermal field is assumed.

Pipeline Right-of-Way Costs There would be no cost to obtain rightof-way for a pipeline between the geopressured-geothermal field and the SCWO plant.

Brine Line cost A brine 7 ine will cost $\$ 250,000$ to transport the hot brine from the geopressured-geothermal field to the SCWO plant.

Gas Transmission Line Because all gas is assumed to be consumed in the SCWO process, no gas will be separated and sold.

Buildings/Site Upgrade For the analysis, a cost of $\$ 350,000$ for development of the geopressured-geothermal/SCWO facility is assumed. The majority of costs would be to develop heavy duty roads, parking lots, and lighting to safely receive hazardous wastes.

Equipment Costs Equipment is the production assets that are easily transported from site to site whereas capital expenditures such as well production costs are site specific. Because the process is in a conceptual stage, most of the equipment costs are proprietary or not obtainable. Engineering studies will have to determine material requirements required that could affect the project viability. When costs are estimated, engineering guides (J. S. Page, 1984) are used in a conservative manner. 
Pumps, Throttles, and Controls

$\$ 45,000$

Waste Storage Tanks and Facility

$3,200,000$

Compressors

225,000

Inlet Pumps

225,000

Inlet Heat Exchanger

600,000

Super Critical Reactor

$1,600,000$

Outlet Heat Exchanger

400,000

Outlet Pumps

150,000

High Pressure Separator

650,000

Gas Turbine/Electric Generator

$1,760,000$

Low Pressure Separator

275,000

Various In-Plant Piping

800,000

Working Funds The analysis assumes start-up costs of $\$ 100,000$ and $\$ 50,000$ for the geopressured-geothermal field and the SCWO facility, respectively.

Predevelopment Contingency The analys is assumes a 20\% predevelopment contingency on all preoperation costs to allow for unforeseen events and associated costs.

Capitalized Interest The analysis assumes all interest from borrowed funds is accrued during the preoperational phase and will be capitalized over the operation life. Capitalized interest is a method where the lender (bank) allows interest to accrue without payment during the preoperational phase.

\section{Operational Variables}

Operational variables are either direct costs that vary with the level of production or indirect costs that are fixed year to year and do not vary with the level of production. Labor, material, and direct maintenance vary with the level of production, although experience indicates that labor is less sensitive to production rates in geothermal 
development. Common indirect costs include administration, insurance, utilities, and indirect maintenance. All operational expenses are inflated annually.

Labor, Administration, Overhead Administration, operations 1abor, and other indirect costs are assumed to be constant for all levels of production. The analysis assumes $\$ 100,000$ for the geopressuredgeothermal field based on previous geothermal experience. The SCWO facility assumes $\$ 605,000$ because of labor intensive activity.

Direct Maintenance Direct maintenance costs are calculated as a percentage of the installed capital cost. The analysis assumes a 3.0 and 7.5\% maintenance percentage for the geopressured-geothermal field and SCWO facility respectively, generating nearly $\$ 950,000$ of maintenance costs annually.

Direct and Indirect Materials The analysis assumes minimum material costs of $\$ 90,000$ and $\$ 100,000$ annually for the geopressured-geothermal field and the SCWO facility, respectively.

Liability and Operator's Insurance The analysis assumes a $\$ 110,000$ and $\$ 250,000$ for insurance premiums for the geopressured-geothermal field and the SCWO facility, respectively.

Data Collection, Lab Analysis The analysis assumes $\$ 240,000$ ( $\$ 120,000$ ea) for data collection and analysis to support continuing production goals and monitor the site for potential hazardous waste releases during operation.

Contingencies A contingency factor of $10 \%$ is assumed on all operating costs to cover the costs of any unforeseen events. The analysis considers this factor conservative because of the relatively high proportion of fixed costs (administration, insurance, labwork) in the operation of both geopressured-geothermal field and the SCWO facility. This contingency is also inflated annually. 
Royalty Royalty is a direct cost of production and is calculated as a percentage of gross revenues. This analysis assumes a royalty of $15 \%$ (also see discussion on site procurement, page 62).

Federal, State, and Local Taxes The analysis assumes that an ad valorem tax of $7.2 \%$, a severance tax of $5.0 \%$, a state tax of $2.0 \%$, and a federal tax of $38.0 \%$ are calculated as a percentage of net income less allowable deductibles.

Production Decline This analysis does not assume a graduated decline in brine production based on the current understanding of the production fields.

Operating Factor An operating factor of $90 \%$ is assumed for both electricity production and disposal service operation. This is calculated as a $95 \%$ availability factor for the geopressured-geothermal well and 95\% availability factor for the SCWO facility $(0.95 \times 0.95=$ $0.90)$.

Operating Rates The analys is assumes the SCWO facility will use $10 \%$ of the 1,000,000 gpd of available geopressured-geothermal brine $(100,000$ gpd) to decompose 10,000 gpd of hazardous waste. Available energy in the form of excess process steam is available to drive a 2,000 KW gas/turbine generator.

\section{Postoperational Variables}

Postoperational variables include a decommissioning cost of $\$ 75,000$ and a plug and abandon cost of $\$ 110,000$ for the geopressured-geothermal well field and a $\$ 300,000$ cost to decommission and monitor the SCWO facility.

These analyses assumes no salvage value for any of the physical assets used in the production of either hot brine or the disposal of hazardous wastes. In addition, all lease and right-of-way agreements are assumed to have no remaining value of the end of the project. 


\section{MOdel Summary}

The model calculates the breakeven cost, discounted payback, and NPV by equating the capital investment and the discounted cash flows over the life of the investment. This overall equation is summarized in the following equation:

Summation of all preoperation and development costs equals

Summation of all discounted, annual revenue streams calculated by:

Total Electricity Revenues

plus Total Disposal Revenues

Annual Gross Revenues

less

Royalty Payment of $1.0 \%$

Net Annual Revenues

less

less

less

less

less

plus

\begin{tabular}{|c|}
\hline $\begin{array}{l}\text { Electricity Production Expenses } \\
\text { Disposal Operation Expenses } \\
\text { Interest Expenses } \\
\text { Depreciation Expenses } \\
\text { Decommission and Plug \& Abandon Costs } \\
\text { Salvage (assumed no salvage in analysis) }\end{array}$ \\
\hline $\begin{array}{l}\text { Net Taxable Income } \\
================================== \\
\text { Severance Tax } \\
\text { Ad Valorem Tax } \\
\text { State Tax } \\
\text { Federal Tax } \\
\text { Depreciation Expenses }\end{array}$ \\
\hline
\end{tabular}




\section{Economic Results}

Assuming a very conservative discount rate of $26 \%$, the breakeven price to develop a viable geopressured-geothermal/SCWO facility is $\$ 0.060 / \mathrm{kWh}$ and $\$ 2.85 / \mathrm{gal}(\$ 0.627 / \mathrm{L})$, both prices higher than currently acceptable market levels found in the assumed Gulf coast location. When current market prices of $\$ 0.020 / \mathrm{kWh}$ and $\$ 1.20 / \mathrm{gal}$ (\$0.264/L) (average) are assumed, the discount period is greater than ten years and the NPV is greater than a negative $\$ 6,000,000$, a net loss of capital to investors.

Economically, the most sensitive variable to the development and use of this technology is risk, a result of technical and engineering uncertainty. Because of the uncertainty, we had to assume a 4 year leadtime before production beings. Because of unproven engineering and operating data, a high discount rate of $26 \%$ is used, reducing any revenue stream by $50 \%$ within 4 years. Because little or no vendor data is available to calculate an installed plant cost, conservative 10 and $20 \%$ contingency factors is assumed. When all of these risk factors are compounded, the total risk overwhelms even the best of cash flows.

When uncertain variables become less uncertain, risk drops, the discount rate drops, contingency factors drop, and breakeven prices drop; project viability increases. Assuming additional research, engineering study, and analysis would increase the knowledge base and substantially reduce the variance of the variables, we would expect breakeven prices to fa11. Two additional cases are summarized below and illustrated in the detailed analysis included in the appendix where risk is substantially reduced and is reflected in the discount rate, plant availability, lead time, and contingency (Table 7). 
Table 7. Breakeven cost for three selected levels of uncertainty.

\begin{tabular}{|c|c|c|c|}
\hline & Breakeven & $\begin{array}{l}\text { Discounted } \\
\text { Payback in years }\end{array}$ & $\begin{array}{l}\text { NPV } \\
\text { in } 000 \text { 's }\end{array}$ \\
\hline $\begin{array}{l}26 \% \text { discount: } \\
20 \% \text { const cont } \\
10 \% \text { oper cont } \\
90 \% \text { cap factor } \\
5 \text { y lead time }\end{array}$ & $\begin{array}{l}\$ 0.060 / \mathrm{KWh} \\
\$ 2.85 / \mathrm{gal}\end{array}$ & 10.0 & $<\$ 12.5$ \\
\hline $\begin{array}{l}\text { current market } \\
\text { analys is as above }\end{array}$ & $\begin{array}{l}\$ 0.020 / \mathrm{KWh} \\
\$ 1.20 / \mathrm{gal}\end{array}$ & 10.0 & $\langle \$ 6,122.0\rangle$ \\
\hline $\begin{array}{l}21 \% \text { discount: } \\
15 \% \text { const cont } \\
7.5 \% \text { oper cont } \\
92.5 \% \text { cap factor } \\
5 \text { y lead time } \\
\$ 0.045 / \mathrm{KWh} \\
\$ 2.25 / \mathrm{gal} \quad 9.7 \\
\$ 151.0\end{array}$ & $\begin{array}{l}\$ 0.045 / \mathrm{KWh} \\
\$ 2.25 / \mathrm{gal}\end{array}$ & 9.7 & $\$ 151.0$ \\
\hline $\begin{array}{l}15 \% \text { discount: } \\
10 \% \text { const cont } \\
5 \% \text { oper cont } \\
95 \% \text { cap factor } \\
1 \text { y lead time }\end{array}$ & $\begin{array}{l}\$ 0.030 / \mathrm{KWh} \\
\$ 1.38 / \mathrm{gal}\end{array}$ & 9.9 & $\$ 181.0$ \\
\hline
\end{tabular}





\section{CONCLUSIONS/RECOMMENDATIONS}

In keeping with the stated goal of the DOE Geopressured-Geothermal Research Program to investigate various applications with the potential for recovering process energy from the three forms of energy contained in the resource, i.e., thermal, hydraulic, and methane gas, this study considers three different high-temperature/high-pressure processes that could potentially be coupled with the resource. The three processes are: a) wet air oxidation (WAO), b) pyrolytic conversion and $c$ ) decomposition/detoxification of hazardous waste by SCWO. The conclusions regarding each process are presented separately.

\section{CONCLUSIONS}

Wet Air Oxidation (WAO)

This process is carried out at subcritical conditions so that less energy input would be required to couple the process to the resource. However, low DREs, requirements for long residence times, and potential for significant levels of environmentally unacceptable emissions in the effluents make this process unsuitable for the proposed application.

\section{Pyrolytic Conversion}

There is a significant processing potential for this process within the vicinity of the resource. The scientific feasibility of the process has been established. However, there are major engineering limitations which make the process unsuitable for further consideration for development.

The process limitations are:

1. Limited throughput because of requirements for relatively long residence times and requirements for batch operation. The latter is caused by materials handling difficulties with many feedstocks. 
2. Char formation typical under many processing conditions.

3. Production of a complex product mixture requiring significant further processing before final utilization.

4. There is currently no indication that the process can be successfully coupled to the resource; the high TDS of the brine is a significant unresolved issue.

\section{Decomposition/Detoxification Process}

There is a significant processing potential for this process within the vicinity of the resource, minimizing transportation costs as a significant factor in the economics. Feedstocks would consist of organic liquids, oils, and sludges.

Processing would occur at SCF conditions, which are above those available directly from the resource. However, the SCWO process would produce more energy than it consumed, providing the potential for additional revenues from the sale of electricity.

For the conceptual, SCWO process studied, the reactor would operate at $1100^{\circ} \mathrm{F}\left(594^{\circ} \mathrm{C}\right)$ and $3700 \mathrm{psia}(251.8 \mathrm{~atm}$ or $25.51 \mathrm{MPa})$ producing rapid, essentially complete oxidation of the organic components present in the fluid. Thus, DREs of $99.999 \%$ or higher could be achieved at reactor residence times of 1 minute or less, producing process effluents that would be environmentaliy innocuous. This gives the SCWO process major advantages over other destruction technologies.

Direct recovery of the excess energy from the process is the most efficient option; however, the required turbine technology is not yet commercially available. Because of the limited market potential, it would not be cost-effective to develop a new turbine design only for this application. Heat exchange to a secondary working fluid coupled to a turbine would be another, less energy efficient option for energy recovery. However, at this time use of a binary cycle system is probably the most realistic design. 
Coupling of the SCWO process to the resource is definitely feasible but has not been successfully demonstrated. The capability of the SCWO process to handle the high salt levels present in the brine has not been successfully demonstrated. Under SCF conditions the inorganic salts will be insoluble and precipitate out. Solids separation and removal in the reactor has not been successfully demonstrated at this level of solids loading. Development work in this area would be required.

Millions of barrels of hydrocarbon, liquid, hazardous waste continues to be disposed of by convenient but environmentally unacceptable methods. The SCWO process is a potentially environmentally benign alternative to the present methods. Additionally, energy could be recovered in large enough quantities to provide cost efficient electrical power. The proposed technology shows tremendous promise of contributing to solving this nation's pollution and energy problems. However, although development of a geopressured-geothermal resource to dispose of these wastes and produce power may prove to be economically viable, analysis suggest that it is uneconomical at this time, primarily because of the undefined technical requirements, capital cost, and operating parameters and the conservative assumptions in analysis.

\section{RECOMMENDATIONS}

Based upon the technical and economic evaluation of the SCWO process coupled to the geopressured-geothermal resource, it is recommended that further studies be conducted to initiate development of this application. Several tasks need to be initiated in the next phase. First, a collaborative agreement needs to be developed with one or more vendors so that their input into future development work is available early on. Experimental studies need to be conducted to resolve the solids handling issue posed by the high TDS loading of the brine. Finally, more detailed analysis of the conceptual process design needs to be undertaken to refine both the process technical requirements and process economics. 
Such as assessment would reduce the technical and economic uncertainties associated with evaluating a future field demonstration of the technology.

From an economic perspective, the additional effort in the technical and engineering evaluation of this technology proposal is recommended. Reduced capital costs, reduced operating costs, increased operating efficiencies and reduced uncertainty of this technology would increase the economic viability of this proposed technology. There are no other specific technical or engineering recommendations at this time because of the overall uncertainty of data.

From a resource perspective, the costs associated with acquiring and reworking the resource may be critical. This issue deserves additional study and analysis to refine its impact on the economic viability of the process. 


\section{REFERENCES}

Benham, C. B. and J. P. Diebold, 1975, "Conversion of Solid Waste to Fuels," NWC TP 5797, Naval Weapons Center, China Lake, CA.

Bilello, L. J., J. D. Crane, L. C. Carter, W. R. Beckwith and A. B. Be11, 1982, Supercritical Fluid Technology Application Study, DRXTHTE-CR-82169, p. 94.

Borchert, R. N. and G. H. Aumus, 1986-1987, "Economic Analys is of Mission Canyon Production, Burke County, N.D.," 0il \& Gas Journal, May, pp. 128-133.

Charpentier, B. A. and M. R. Sevenants (eds.), 1988, Supercritical Fluid Extraction and Chromatography Techniques and Applications, ACS Symposium Series \#366, Washington D.C.; American Chemical Society, p. 253.

Connelly, J. F., 1966, "Solubility of Hydrocarbons in Water Near the Critical Solution Temperature," Journal of Chemical Engineering Data, $\underline{11}, 1$, pp. 13-16.

EA-Mueller, Inc. and Energetics, Incorporated, 1989, Research and Development Opportunities in Supercritical Fluid Technology: Final Report: Proceedings of a Workshop Held on December 2, 1988, Washington, D.C., CONF-881296-Summ, (DE89015320), p. 24.

Franck, E. U., 1976, "Properties of Water," High Temperature High Pressure Electrochemistry in Aqueous Solutions, University of Surrey, England, NACE-4, pp. 109-116.

Helling, R. K. and J. W. Tester, 1988, "Oxidation of Simple Compounds and Mixtures in Supercritical Water: Carbon Monoxide, Ammonia, and Ethanol," Environmental Science and Technology, 22, 11, pp. 13191324 .

Johnston, K. P. and J. M. L. Penninger (eds.), 1989, Supercritical Fluid Science and Technology, ACS symposium Series \#406, Washington, D.C.: American Chemical Society, p. 550.

Johnston, J. B., R. E. Hannah, V. L. Cunningham, B. P. Daggy, F. J. Sturm and R. M. Kelly, 1988, "Destruction of Pharmaceutical Wastes by the MODAR Supercritical Water Oxidation Process, "Bio/Technology, $\underline{6}$, pp. 1423-1427.

Lucke, R. and E. Toder, 1987, "Assessing the U.S. Federal Tax Burden on $0 i 1$ and Gas Extraction," The Energy Journal, 8 , 4, October, pp. 51-64. 
Martynova, 0. I., 1976, "Solubility of Inorganic Compounds in Subcritical and Supercritical Water, " High Temperature High Pressure Electrochemistry in Aqueous Solutions, University of Surrey, England, 2, NACE-4 1976, pp. 131-138.

McCoy and Associates, Inc., 1989, The Hazardous Waste Consultant, I, 5, September/0ctober, pp. 1-5.

McFarland, J. M. et al., 1972, "Comprehensive Studies of Solid Waste Management," SERL Report No. 72-3, National Environmental Research Corporation, Contract 2 ROI-EC-00250-01, Environmental Protection Agency, May.

McHugh, M. A. and V. J. Krukonis, 1986, Supercritical Fluid Extraction Principles and Practice, Boston: Butterworths, p. 507.

Mode11, M., G. G. Gaudet, M. Simson, G. T. Hong, and K. Bieman, 1983, "Destruction of Hazardous Waste Using Supercritical Water," Incineration and Treatment of Hazardous Waste: Proceedings of the Eighth Annual Research Symposium, Ft. Mitchell, Kentucky, D.W. Shultz (ed.), EPA-600/9-83-003, Apri1, pp. 202-212.

Mode11, M., 1985 "Gasification and Liquefaction of Forest Products in Supercritical Water," in Fundamentals of Thermochemical Biomass Conversion, R. P. Overend, T. A. Milne and L. K. Mudge (eds.), New York: Elsevier Applied Science Publishers, pp. 95-119.

Negus-de Wys, J. and M. Dorfman, 1990, "The Geopressured-Geothermal Resource: Transition to Commercialization," Geothermal Resource Council Meeting, Kona Surf, Hawai i, August, p. 9.

Page, J. S., 1984, Conceptual Cost Estimating Manual, Houston, Texas: Gulf Publishing Company, p. 332.

Paulaitis, M. E., J. M. L. Penninger, R. D. Gray, Jr. and P. Davidson (eds.), 1983, Chemical Engineering at Supercritical Fluid Conditions, Ann Arbor, Michigan: Ann Arbor Science, p. 543.

Penniger, J. M. L., M. Radosz, M. A. McHugh and V. J. Krukonis (eds.), 1985, Supercritical Fluid Technology, Process Technology Proceeding, 3, New York: Elsevier, p. 464.

Pitzer, K. S. and R. T. Pabalan, 1986, "Thermodynamics of $\mathrm{NaCl}$ in Steam, " Geochimica et Cosmochimica Acta, 50, pp. 1445-1454.

Quist, A. S. and W. L. Marsha11, 1965, "Estimation of the Dielectric Constant of Water to $800^{\circ}$, " Journal of Physical Chemistry, $\underline{69}$, 9, pp. 3165-3167.

Rofer, C. K., 1987, Kinetics Experiments and Bench-Scale System Background, Design, and Prel iminary Experiments, LA-11106-MS, DOE/HWP-42, September 30, p. 33. 
Rofer, C. K. and G. E. Streit, 1988, Kinetics and Mechanism of

Methane 0xidation in Supercritical Water, LA 11439-MS, DOE/HWP-64, September, p. 27.

Rofer, C. K. and G. E. Streit, 1989, Phase II Final Report: 0xidation of Hydrocarbons and Oxygenates in Supercritical Water, LA-11700-MS DOE/HWP-90, September 30, p. 48.

Rofer, C. K. and J. D. Wander (eds.), 1989, Proceedings of the Workshop on Supercritical Fluid Processing of High Risk Wastes, (Draft), Los Alamos, New Mexico, August 1-2, p. 109.

Rofer, C. K., 1990, "Destruction of Hazardous Waste by Supercritical Water 0xidation," Proceedings of the First Meeting of the Industrial Consortium for the Utilization of the Geopressured-Geothermal

Resource, Rice University, Houston, Texas, January 10, J. Negus-de Wys (ed.), 2, March, pp. 78-98.

Sanner, W. S. et al., 1970, "Conversion of Municipal and Industrial Refuse into Useful Materials by Pyrolysis," RI 7428, BUMINES.

Schneider, G. M., E. Stahl and G. Wilke (eds.), 1980, Extraction With Supercritical Gases, Deerfield Beach, Florida: Verlag Chemie, p. 189.

Simoneit, B. R. T. and P. F. Lonsdale, 1982, "Hydrothermal Petroleum in Mineralized Mounds at the Seabed of Guaymas Basin," Nature, 295, 5846, January 21, pp. 198-202.

Simoneit, B. R. T., 1983, "Organic Matter Maturation and Petroleum Genesis: - Geothermal versus Hydrothermal, "Geothermal Resources Council, SPECIAL REPORT NO. 13, May, pp. 215-241.

Simoneit, B. R. T., 1984a, "Hydrothermal Effects on Organic Matter High vs Low Temperature Components," Orqanic Geochemistry, $\underline{6}$, pp. 857-864.

Simoneit, B. R. T., 1984b, "Effects of Hydrothermal Activity on Sedimentary Organic Matter: Guaymas Basin, Gulf of California Petroleum Genes is and Protokerogen Degradation," Hydrothermal Processes at Seafloor Spreading Centers, New York Plenum Publishing Corporation, pp. 451-471.

Simoneit, B. R. T., R. P. Philp, P. D. Jenden, and E. M. Galimov, 1984c, "Organic Geochemistry of Deep Sea Drilling Project Sediments from the Gulf of California - Hydrothermal Effects on Unconsolidated Diatom Ooze," Organic Geochemistry, 7, 3/4, pp. 173-205.

Simoneit, B. R. T. and E. C. Galimov, 1984d, "Geochemistry of Interstitial Gases in Quaternary Sediments of the Gulf of California," Chemical Geology, 43, pp. 151-166.

Simoneit, B. R. T., 1985a, "Hydrothermal Petroleum: Composition and 
Utility as a Biogenic Carbon Source," Biological Society of Washington Bulletin, 6, pp. 49-56.

Simoneit, B. R. T., 1985b, "Hydrothermal Petroleum: Genesis, Migration, and Deposition in Guaymas Basin, Gulf of California," Canadian Journal of Earth Sciences, 22, 12, pp. 1919-1929.

Squires, T. G. and M. E. Paulaitis (eds.), 1987, Supercritical Fluids Chemical and Engineering Principles and Applications, ACS Symposium Series \#329, Washington, D.C.: American Chemical Society, p. 302.

Staszak, C. N., K. C. Malinowski and W. R. Killilea, 1987, "The Pilot-Scale Demonstration on the MODAR Oxidation Process for the Destruction of Hazardous Organic Waste Materials, "Environmental Progress, $\underline{6}, 2$, pp. 39-43.

Stone and Webster Engineering Corporation, 1989, Assessment and Development of an Industrial Wet Oxidation System for Burning Waste and Low-Grate Fuels, DOE/ID-12711-1, September.

Thomason, T. B. and M. Mode 11, 1984, "Supercritical Water Destruction of Aqueous Wastes," Hazardous Waste, 1, 4, pp. 453-467.

Thomason, T. B., G. T. Hong, K. C. Swallow and W. R. Killilea, 1988, "The MODAR Supercritical Water 0xidation Process," submitted to : Innovative Hazardous Waste Treatment Technology Series, H. Freeman (ed.), p. 33 .

U. S. Department of Commerce, Bureau of Economic Analysis, 1989, Survey of Current Business, February.

U. S. Internal Rescue Service, Publication 534, 1988.

U. S. Department of Commerce/International Trade Commission, 1989 Industrial Out look. Prospects for over 350 Industries, 30th Annual Edition.

Uematsu, M. and E. U. Franck, 1980, "Static Dielectric Constant of Water and Steam," Journal of Physical and Chemical Reference Data, $\underline{9}$, 4, pp. $1291-1306$.

Wall Street Journal, 1990, Section C, Money Rates, Dow.Jones and Company Western Edition, August.

Welhan, J. A. and J. E. Lupton, 1987, "Light Hydrocarbon Gases in Guaymas Basin Hydrothermal Fluids: Thermogenic versus Abiogenic Origin," The American Association of Petroleum Geologist Bulletin, 71, 2, February, pp. 215-223.

Whelan, J. K., B. R. T. Simoneit, and M. E. Tarafa, 1988, "C $-C_{8}$ Hydrocarbons from Guaymas Basin, Gulf of California - Comparison to 
Peru Margin, Japan Trench and California Borderlands, " Organic Geochemistry, 12, 2, pp. 171-194.

Wilhelmi, A. R. and P. V. Knopp, 1979, "Wet Air Oxidation - An Alternative to Incineration," Chemical Engineering Progress, 75,8 , pp. 46-52. 


\section{APPENDIX A}

\section{RESULTS OF ECONOMIC ANALYSIS}

A-1 


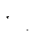


ANALYSIS OF WELL: Typical Geopressured-Geothermal Well

26-Sep-90: date MODEL NAME: GG10-B1

MODEL ANALYSIS: electricity production and SCWO reduction of hazardous waste

RESULTS :
$10-$ YR NPV
Discounted Payback
$\$ 12,578$
10.0 years
1990

BASE YEAR and CONTRACT DOLLARS :

FINANCIAL SUMMARY:

TOTAL PRE-OPERATION/DEVELOPMENT/CAPITAL COSTS . . . . \$18,334,185

$\begin{array}{lr}\text { Borrowed } & 5,700,238 \\ \text { Owners Equity } & 12,320,434 \\ \text { Capitalized Interest } & 313,513\end{array}$

INVESTMENTS/EXPENSES/REVENUES :

TOTAL PRE-OPERATION/DEVELOPMENT/CAPITAL COSTS

TOTAL ENV ASSESS \& PUBLIC COMMENT . . 2,783,156

TOTAL DEVELOPMENT COST.

Geopressured-Geotherma i 2,546,486

Pipe line R ight-of-Way
TOTAL CAPITAL BUILDING/EQUIPMENT COST.

\section{$9,687,585$}

Geopressured-Geotherma I $\quad 1,148,653$ Disposal

$8,538,931$

CONTINGENCIES

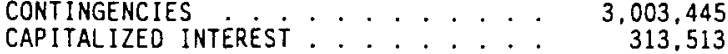

$3,003,445$

GROSS OPERATING REVENUES .............. . $\$ 11,838,599$

TOTAL COSTS $(y r-1) \ldots . . . .652,481$

Electricity 750,727

Disposal 901,754

TOTAL REVENUES $(y \mathrm{r}-1) \ldots . \cdot 173,13,491,079$

$\begin{array}{lr}\text { Electricity } & 1,173,139 \\ \text { Disposal } & 12,317,941\end{array}$

$\$ 18,334,185$

TOTAL POST-OPERATION COSTS ........... \$790,014

SALVAGE (at end of project life) ......... \$O

$26.0 \%$

$40.0 \%$

$11.0 \%$

7 yrs

7 yrs

$1.0 \%$

$38.0 \%$

$2.0 \%$

$5.0 \%$

$7.2 \%$

$5.0 \%$

$0.0 \%$

$0.0 \%$

$0.5 \%$

$2.0 \%$

GEOPRESSURED-GEOTHERMAL WELL CHARACTERISTICS : Brine Temp o Surface $300 \mathrm{~F}$ Barrels per Day

Gas Concentration / Barrel $35 \mathrm{scf} / \mathrm{B}$

Gas Quality

Well Life

$90 \%$

$10 \mathrm{yrs}$

REVENUE CHARACTERISTICS :

Generator Capacity $\quad 2000 \mathrm{KW}$

KWh selling price

disposal volume

average disposal cost

$\$ 0.060 \mathrm{kWh}$

$10,000 \mathrm{gal} / \mathrm{da}$

$\$ 2.85 / \mathrm{ga} 1$ 
MODEL INPUTS :

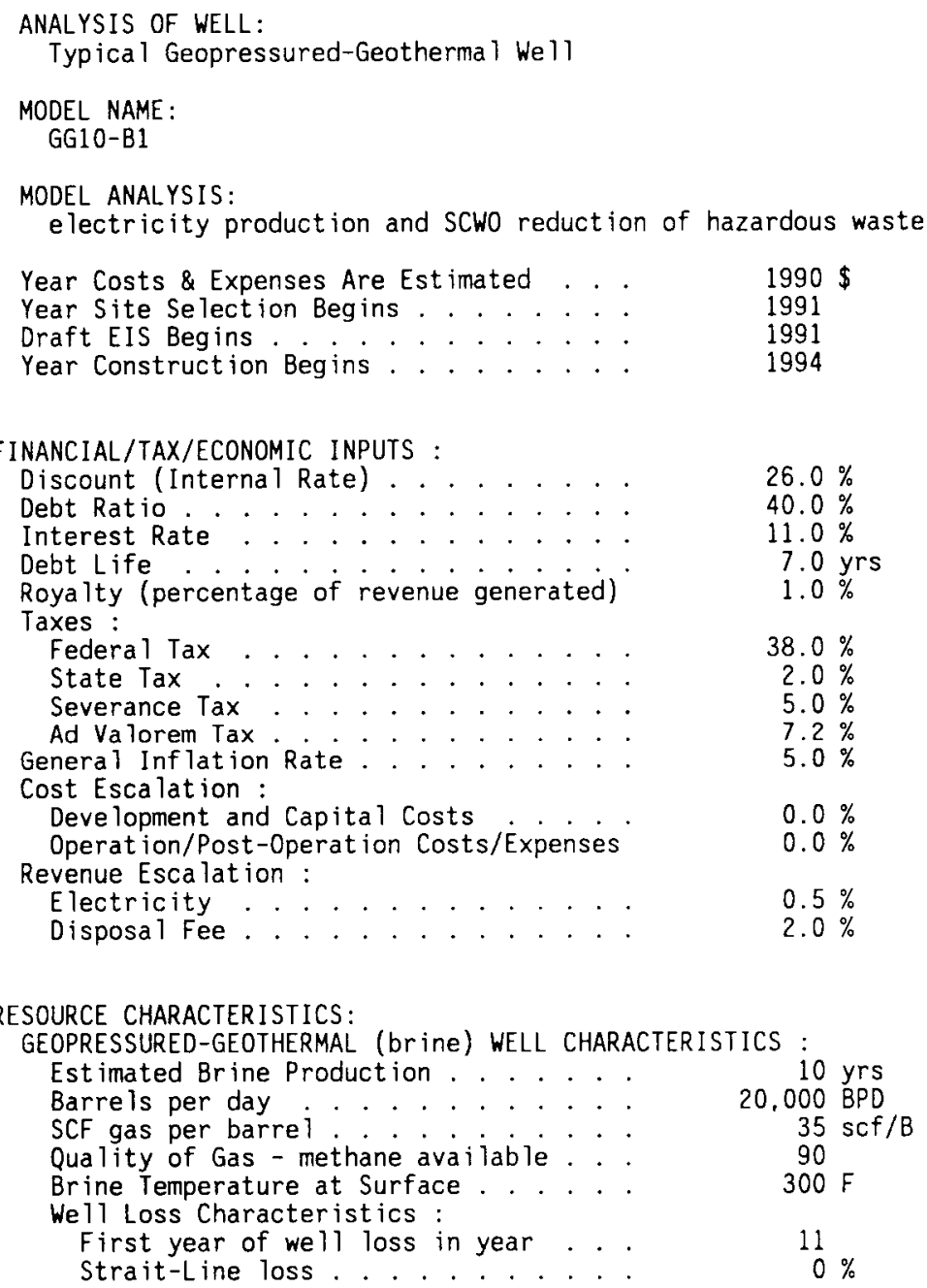


Disposal Site Selection . . . . . . .

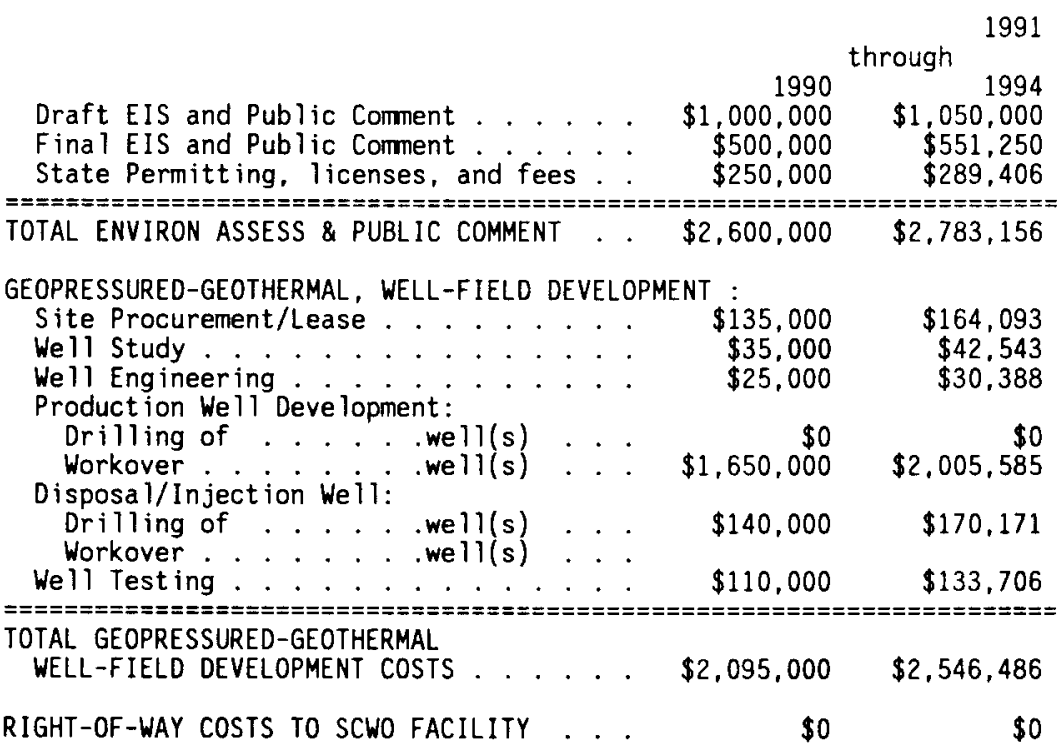

GEOPRESSURED-GEOTHERMAL, CAPITAL BUILDING \& EQUIPMENT :

Site Upgrade, Roads, Bldgs ....... $\$ 350,000$

Brine Line to Disposal/Injection weil: $\$ 100,000$

Brine Line to SCWO . . . . . . . . $\$ 350,000$

Gas Transmission line off-site. . . . . . $\$ 350, \$ 0$

Capital Equipment:

Pumps/Throttles/Ctrls

$\$ 45,000$

$\$ 425,427$

$\$ 121,551$

$\$ 425,427$

Press Separator-Dehyd

$\$ 45,000$

$\$ 0$

Computer......

$\$ 0$

other

$\$ 0$

WORKING FUNDS (Start-up Costs) . . . . $\$ 100,000$

$\$ 100,000 \quad \$ 121,551$

$==========================$
TOTAL GEOPRESSURED-GEOTHERMAL

CAPITAL BUILDING AND EQUIPMENT COSTS . . $\$ 945,000 \quad \$ 1,148,653$

SCWO OFACILITY CAPITAL BUILDING \& EQUIPMENT :

Brine Line to Injection Wells .....

Capital Equipment:

Waste Storage Facility.

Compressors ....

In let Pumps . . . . .

In let Heat Exc $: . . \cdot$.

Super Critical Reactor.

Out let Heat Exc ....

Out let Pumps . . . . . .

High Press Separator.

Gas Turbine/E lect Gen

Low Press Separator.

In-plant Piping . . . .
Other

$\$ 3,200,000$

$\$ 225,000$

$\$ 225,000$

$\$ 600,000$

$\$ 1,600,000$

$\$ 400,000$

$\$ 150,000$

$\$ 650.000$

$\$ 1,800,000$

$\$ 275,000$

$\$ 800,000$

other $\$ 0$

WORKING FUNDS (Start-up Costs) . . . . \$ \$150,000 \$182,326

$========================+1$
TOTAL SCWO CAPITAL BUILOING

AND EQUIPMENT COSTS .......... $\$ \$ 7,025,000 \quad \$ 8,538,931$

TOTAL PRE-OPERATION COSTS:

$\$ 150,000$

$\$ 182,326$

$\$ 6,725,000$

$\$ 8,174,280$ $\$$ 


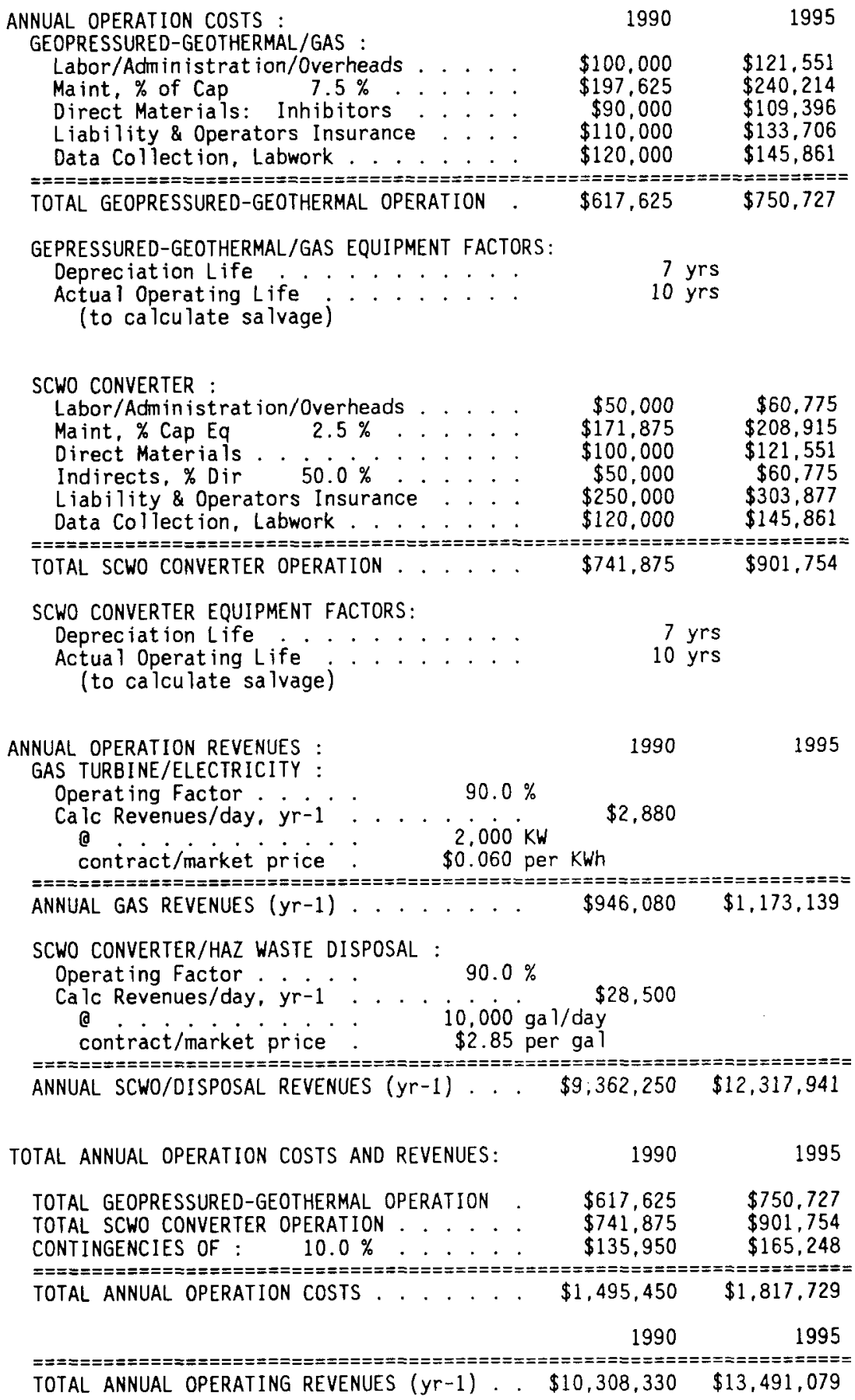


ANALYSIS OF WELL: Typical Geopressured-Geothermal We 11

26-Sep-90: date MODEL NAME: GG10-B1

MODEL ANALYSIS: electricity production and SCWO reduction of hazardous waste - NPV/Dis Payback analysis

RESULTS :
10-YR NPV
Discounted Payback
$(\$ 6,122,674)$
$>10$ y years

BASE YEAR and CONTRACT DOLLARS :

1990

FINANCIAL SUMMARY:

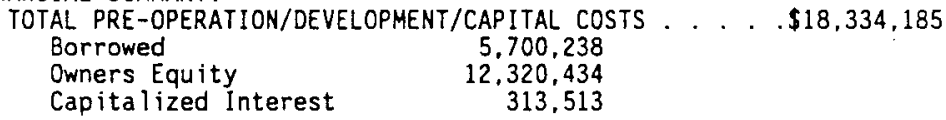

INVESTMENTS/EXPENSES/REVENUES :

TOTAL PRE-OPERATION/DEVELOPMENT/CAPITAL COSTS . . . . \$18,334,185

TOTAL ENV ASSESS \& PUBLIC COMMENT $\quad . \quad . \quad 2,783.156$

TOTAL DEVELOPMENT COST.

Geopressured-Geotherma i 2,546,486 Pipeline Right-of-Way 0

TOTAL CAPITAL BUILDING/EQUIPMENT COST.

\subsection{7 .585}

Geopressured-Geotherma l $1,148,653$ Disposal

$8,538,931$

CONTINGENCIES

.. .

$3,003,445$

CAPITAL IZED INTEREST $\ldots 313,513$

GROSS OPERATING REVENUES ............ $\$ 4,022,828$

TOTAL COSTS $(y \mathrm{r}-1) \ldots \ldots . . . . .652,481$

Electricity $\quad 750,727$ Disposal 901,754

TOTAL REVENUES $(y r-1) \quad \ldots . . \cdot 3,675,309$

Electricity $\quad 488,808$

Disposal $5,186,501$

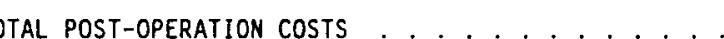

$\$ 790,014$

SALVAGE (at end of project life)

FINANCIAL/TAX/ECONOMIC INPUTS :

$\begin{array}{lr}\text { Discount Rate (IRR) } & 26.0 \% \\ \text { Debt Ratio } & 40.0 \% \\ \text { Interest Rate } & 11.0 \% \\ \text { Debt Life } & 7 \mathrm{yrs} \\ \text { Depreciation Life } & 7 \mathrm{yrs} \\ \text { Royalty (\% of revenue) } & 1.0 \%\end{array}$

Taxes:

Federal Tax $38.0 \%$

State Tax $2.0 \%$

Severance Tax $\quad 5.0 \%$

Ad Valorem Tax $\quad 7.2 \%$

Inflation Rate $\quad 5.0 \%$

Cost Escalation

Development and Capital Cost $0.0 \%$

op/Post-op Costs \& Expenses $0.0 \%$

Revenue Escalation:

- Electricity

$0.5 \%$

Hazardous Waste Disposal $2.0 \%$

GEOPRESSURED-GEOTHERMAL WELL CHARACTERISTICS : Brine Temp a Surface $300 \mathrm{~F}$ Barrels per Day 20,000 BPD

Gas Concentration / Barrel $35 \mathrm{scf} / \mathrm{B}$ Gas Quality $\quad 90 \%$ Well Life

$10 \mathrm{yrs}$

REVENUE CHARACTERISTICS :

Generator Capacity $\quad 2000 \mathrm{KW}$

KWh selling price

disposal volume

average disposal cost

$10.025 / \mathrm{KWh}$

$10.000 \mathrm{ga} \mathrm{l} / \mathrm{da}$

$\$ 1.20 / \mathrm{ga} 1$ 
ANALYSIS OF WELL: Typica1 Geopressured-Geothermal We 11

MODEL ANALYSIS: electricity production and SCWO reduction of hazardous waste - LOW RISK SCENARIO

RESULTS :

10-YR NPV

Discounted Payback

$\$ 181,491$

9.9 years

BASE YEAR and CONTRACT DOLLARS :

1990

FINANCIAL SUMMARY:

TOTAL PRE-OPERATION/DEVELOPMENT/CAPITAL COSTS . . . . \$15,489,013

Borrowed

Owners Equity

Capitalized Interest

$4,739,427$

$10,488,917$

260,668

INVESTMENTS/EXPENSES/REVENUES

TOTAL PRE-OPERATION/DEVELOPMENT/CAPITAL COSTS

TOTAL ENV ASSESS \& PUBLIC COMMENT . . 2.747.287

TOTAL DEVELOPMENT COST ........ 2,309,738 Geopressured-Geotherma i $2,309,738$ Pipeline Right-of-Way

TOTAL CAPITAL BUILDING/EQUIPMENT COST. $\begin{array}{ll}\text { Geopressured-Geotherma I } & 1,041,863 \\ \text { Disposal } & 7,745,063\end{array}$

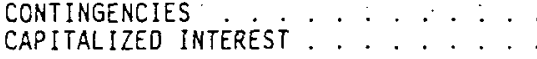

$8,786,925$

$1,384,395$

260,668

GROSS OPERATING REVENUES

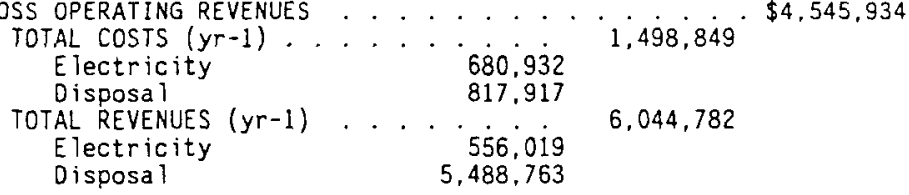

TOTAL POST-OPERATION COSTS .............. \$790.014

SALVAGE (at end of project life) . . . . . . . .
$\$ 15,489,013$

$\$ 0$
FINANCIAL/TAX/ECONOMIC INPUTS :

Discount Rate (IRR)

Debt Ratio

Interest Rate

Debt Life

Depreciation Life

Royalty ( $\%$ of revenue)

Taxes :

Federal Tax

State Tax

Severance Tax

Ad Valorem Tax

Inflation Rate

Cost Escalation :

Development and Capital Cost

Op/Post-0p Costs \& Expenses

$15.0 \%$

$40.0 \%$

$11.0 \%$

7 yrs

7 yrs

$1.0 \%$

$38.0 \%$

$2.0 \%$

$5.0 \%$

$7.2 \%$

$5.0 \%$

$0.0 \%$

$0.0 \%$

Revenue Escalation:

Electricity

$0.5 \%$
$2.0 \%$

Hazardous Waste Disposal

GEOPRESSURED-GEOTHERMAL WELL CHARACTERISTICS : Brine Temp o Surface $300 \mathrm{~F}$

Barre is per Day

Gas Concentration / Barre

Gas Quality

20.000 BPD

$35 \mathrm{scf} / \mathrm{B}$

$90 \%$

10 yrs

REVENUE CHARACTERISTICS :

Generator Capac ity

KWh selling price

disposal volume

average disposal cost

$2000 \mathrm{KW}$

$\$ 0.030 / \mathrm{KWh}$

$10,000 \mathrm{ga} \mathrm{l} / \mathrm{da}$

$\$ 1.38$ /gal 
ANALYSIS OF WELL: Typical Geopressured-Geothermal We 1]

26-Sep-90: date

MODEL NAME: GG10-B3

MODEL ANALYSIS: electricity production and SCWO reduction of hazardous waste - lower $r$ isk scenario

RESULTS

10-YR NPY

Discounted Payback

$\$ 151.000$

9.7 years

BASE YEAR and CONTRACT DOLLARS :

1990

FINANCIAL SUMMARY:

TOTAL PRE-OPERATION/DEVELOPMENT/CAPITAL COSTS . . . .\$17,570,261

$\begin{array}{lr}\text { Borrowed } & 5,462,728 \\ \text { Owners Equity } & 11,807,082 \\ \text { Capitalized Interest } & 300,450\end{array}$

INVESTMENTS/EXPENSES/REVENUES :

TOTAL PRE-OPERATION/DEVELOPMENT/CAPITAL COSTS . . . \$17,570,261

TOTAL ENV ASSESS \& PUBLIC COMMENT ...2,783,156

TOTAL DEVELOPMENT COST ........ 2, . 2,546,486 Geopressured-Geotherma i $2,546,4 \dot{8} 6$

Pipeline Right-of-Way

TOTAL CAPITAL BUILDING/EQUIPMENT COST.

$9,687,585$ Geopressured-Geotherma I

$1,148,653$

Disposa?

$8,538,931$

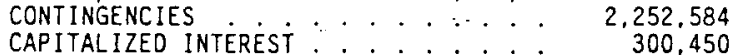

GROSS OPERATING REVENUES . . . . . . . . . . . . \$9,246,634

TOTAL COSTS $(y r-1) \cdots$
E lectricity

Disposa I 901,754

TOTAL REVENUES $(y r-1) \ldots .$.
E lectricity

Disposal $9,994,820$

TOTAL POST-OPERATION COSTS ............ \$790,014

SALVAGE (at end of project life) ........... $\$ 0$
FINANCIAL/TAX/ECONOMIC INPUTS :

$\begin{array}{lr}\text { Discount Rate (IRR) } & 21.0 \% \\ \text { Debt Ratio } & 40.0 \% \\ \text { Interest Rate } & 11.0 \% \\ \text { Debt Life } & 7 \mathrm{yrs} \\ \text { Depreciation Life } & 7 \mathrm{yrs} \\ \text { Royalty (\% of revenue) } & 1.0 \%\end{array}$

Taxes

Federal Tax

State Tax

Severance Tax

Ad Valorem Tax

Inflation Rate

Cost Escalation :

Development and Capital Cost Op/Post-0p Costs \& Expenses

$38.0 \%$

$2.0 \%$

$5.0 \%$

$7.2 \%$

$5.0 \%$

$0.0 \%$

$0.0 \%$

Revenue Escalation :

Electricity

Hazardous Waste Disposa

$0.5 \%$

$2.0 \%$

GEOPRESSURED-GEOTHERMAL WELL CHARACTERISTICS : Brine Temp a Surface $300 \mathrm{~F}$

Barrels per Day

Gas Concentration / Barrel

Gas Quality

Well Life

$20,000 \mathrm{BPD}$

$35 \mathrm{scf} / \mathrm{B}$

$90 \%$

10 yrs

REVENUE CHARACTERISTICS :

Generator Capacity

KWh selling price

disposal volume

average disposal cost
$2000 \mathrm{KW}$ $\$ 0.045 / \mathrm{KWh}$

$10.000 \mathrm{gal} / \mathrm{da}$

$\$ 2.25 / \mathrm{gal}$ 
APPENDIX B

CONVERSION TABLE

B-1 

CONVERSION TABLE

\begin{tabular}{|c|c|c|}
\hline To convert from & to & multiply by \\
\hline atm & psi & 14.6960 \\
\hline atm & $\mathrm{kPa}$ & 101.325 \\
\hline bbl & gal & 42 \\
\hline Btu & $\mathrm{kJ}$ & 1.054340 \\
\hline Btu/gal & $\mathrm{kJ} / \mathrm{L}$ & 0.231929 \\
\hline Btu/1b & $\mathrm{kJ} / \mathrm{kg}$ & 2.32600 \\
\hline${ }^{\circ} \mathrm{C}$ & ${ }^{\circ} \mathrm{F}$ & $1.80000+32$ \\
\hline $\mathrm{ft}^{3}$ & $\mathrm{~L}$ & 28.3168 \\
\hline gal & L & 4.54596 \\
\hline $\mathrm{g} / \mathrm{cm}^{3}$ & $1 \mathrm{~b} / \mathrm{ft}^{3}$ & 62.4280 \\
\hline gpm & $L / S$ & 0.0757660 \\
\hline hp & We & 746.000 \\
\hline $1 b$ & g & 453.592 \\
\hline $1 b$ & $\mathrm{~kg}$ & 0.453592 \\
\hline 1b/gal & $\mathrm{g} / \mathrm{cm}^{3}$ & 0.119826 \\
\hline $\mathrm{mg} / \mathrm{L}$ & $1 \mathrm{~b} / \mathrm{ft}^{3}$ & 0.0624280 \\
\hline $\mathrm{mg} / \mathrm{L}$ & $1 \mathrm{~b} / \mathrm{ga} 1$ & $8.34517 \times 10^{-6}$ \\
\hline Mt & $\mathrm{kg}$ & 1000 \\
\hline $\mathrm{mL} / \mathrm{h}$ & gph & $2.64172 \times 10^{-4}$ \\
\hline MWe & hp & 1340.48 \\
\hline scf/gal & $\mathrm{Nm}^{3} / \mathrm{L}$ & $5.70673 \times 10^{-3}$ \\
\hline
\end{tabular}

